\title{
Certificates of Confidentiality: Protecting Human Subject Research Data in Law and Practice
}

\author{
Leslie E. Wolf*, Mayank J. Patel, \\ Brett A. Williams, Jeffrey L. Austin, \\ Lauren A. Dame
}

\begin{abstract}
Researchers often require and collect sensitive information about individuals to answer important scientific questions that impact individual health and well-being and the public health. Researchers recognize they have a duty to maintain the confidentiality of the data they collect and typically make promises, which are documented in the consent form. The legal interests of others, however, can threaten researchers' promises of confidentiality, if they seek access to the data through subpoena. Certificates of Confidentiality (Certificates), authorized by federal

(C) 2013 Leslie E. Wolf, Mayank J. Patel, Brett A. Williams, Jeffrey L. Austin \& Lauren A. Dame

* Leslie E. Wolf, JD, MPH is Professor of Law, Georgia State University College of Law and the Center for Law, Health \& Society; Mayank J. Patel, Brett A. Williams, and Jeffrey L. Austin are 2012 graduates of Georgia State University College of Law who served as graduate research assistants on this project from 2010-2012; Lauren A. Dame, JD, MPH is Associate Director, Genome Ethics, Law \& Policy at Duke University's Institute for Genome Science $\&$ Policy, and a Senior Lecturing Fellow at Duke Law School. This project was supported by Award Number R01HG005087 from the National Human Genome Research Institute (NHGRI). The content is solely the responsibility of the authors and does not necessarily represent the official views of NHGRI or the National Institutes of Health. The authors would like to thank Laura Beskow, MPH, PhD, the principal investigator on this study, for her leadership; in addition, they would like to thank Dr. Beskow and their other colleagues on the project, Kevin Weinfurt, $\mathrm{PhD}$, Alexandra Cooper, $\mathrm{PhD}$, Emily Namey, MA, and Devon Check, BA, for their input and support. The authors would also like to thank the expert advisory group for their helpful comments and suggestions throughout this project: Mark Barnes, JD, LLM, John Falletta, MD, William E. Freeman, JD, Bernard L, MD, John Merz, MBA, JD, PhD, Lawrence Muhlbaier, PhD, Pearl O'Rourke, MD, Mark Rothstein, JD, Marjorie Speers, $\mathrm{PhD}$, and Jeremy Sugarman, MD.
\end{abstract}


statute, are an important tool for protecting individually identifiable sensitive research data from compelled disclosure. However, questions persist in the research community about the strength of Certificate protections, and the evidence on which to judge the strength is scant. In this article, we address those questions through a careful examination of the legislation and regulations concerning Certificates and the reported and unreported cases we have identified through our legal research and interviews with legal counsel about their experiences with Certificates. We also analyze other statutes that protect research data to compare them to the Certificate's protections, and we review other legal strategies available for protecting research data. Based on our analysis, we conclude with recommendations for how to strengthen protection of sensitive research data.

INTRODUCTION 12

I. RESEARCHERS' CONFIDENTIALITY OBLIGATIONS ..... 18

II. CERTIFICATES OF CONFIDENTIALITY ......................... 20

A. Legislative Authority ............................................. 21

B. Regulatory Authority ...............................................25

C. Reported Cases Involving Certificates ....................... 27

D. Unreported Cases Involving Certificates.................... 36

E. Implications of the Cases........................................... 47

III. OTHER STATUTORY CONFIDENTIALITY

PROTECTIONS ….................................................... 52

A. Federal Statutes....................................................... 52

1. Protection of Substance Abuse Records ................ 52

2. Protection of Federal Research Data .................... 55

B. State Statutes...................................................... 59

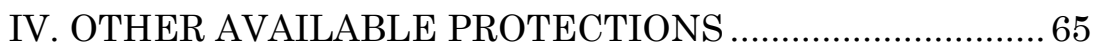

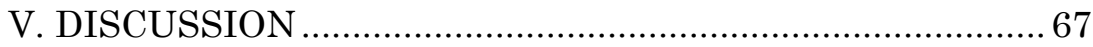

A. Waiver of Confidentiality Protections ........................67 67

B. Identifiability ........................................................... 74

C. Potential Ways for Strengthening the Protections of Identifiable Research Data.................................. 82

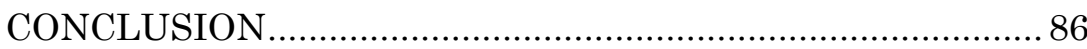

\section{INTRODUCTION}

Researchers often require and collect sensitive information about individuals to answer important scientific questions that 
impact individual health and well-being, and the public health. For example, developing effective drug treatment programs requires understanding how, when, and why people use and obtain drugs. Without people's willingness to share information about their sexuality, sexual behaviors, and drug-using behaviors, we would not have discovered how HIV spread and effective ways to prevent it. In these and numerous other contexts, ${ }^{1}$ researchers recognize they have a duty to maintain the confidentiality of the data they collect and typically make promises,

1. Frequently Asked Questions (FAQs) on Certificates of Confidentiality, OFFICE OF EXTRAMURAL RESEARCH, NAT'L INSTS. HEALTH (June 20, 2011), http:/grants.nih.gov/grants/policy/coc/faqs.htm [hereinafter FAQs on Certificates]. The NIH website on Certificates of Confidentiality recognizes the broad range of research that may collect sensitive, identifiable research data. Its "illustrative" list of research areas that are eligible for a Certificate includes:

[r] esearch on HIV, AIDS and other STDS; [s]tudies that collect information on sexual attitudes, preferences, or practices; [s]tudies on the use of alcohol, drugs, or other addictive products; [s]tudies that collect information on illegal conduct; [s]tudies that gather information that if released could be damaging to a participant's financial standing, employability, or reputation within the community; [r]esearch involving information that might lead to social stigmatization or discrimination if it were disclosed; [r] esearch on participants' psychological well being or mental health; [g]enetic studies, including those that collect and store biological samples for future use; [and] [r] esearch on behavioral interventions and epidemiologic studies.

Id. See also Leslie E. Wolf \& Bernard Lo, Practicing Safer Research: Using the Law to Protect the Confidentiality of Sensitive Research Data, IRB: ETHICS \& HUM. RES., Sept.-Oct. 1999, at 4, 4-7 (discussing the legal protections available to protect sensitive research); Gary B. Melton, Certificates of Confidentiality Under the Public Health Service Act: Strong Protection but Not Enough, 5 VIOLENCE \& VICTIMS 67, 68-69 (1990) (discussing the expanded scope of certificates of confidentiality "beyond mental health and substance abuse research"); Kimberly Hoagwood, The Certificate of Confidentiality at the National Institute of Mental Health: Discretionary Considerations in Its Applicability in Research on Child and Adolescent Mental Disorders, 4 ETHICS \& BEHAV. 123, 123-24 (1994) (discussing the application of Certificates of Confidentiality to mental disorder research); M. Justin Coffey \& Lainie Ross, Human Subjects Protections in Genetic Research, 8 GENETIC TESTING 209, 209-10 (2004) (focusing on the use of Certificates of Confidentiality for research using genetic information); Zachary N. Cooper et al., Certificates of Confidentiality in Research: Rationale and Usage, 8 GEnetiC TESTING 214, 214 (2004); Charles L. Earley \& Louise C. Strong, Certificates of Confidentiality: A Valuable Tool for Protecting Genetic Data, 57 AM. J. HUM. GeneTICs 727, 727 (1995); Kristin F. Lutz et al., Use of Certificates of Confidentiality in Nursing Research, $32 \mathrm{~J}$. NURSING SCHOLARSHIP 185, 185 (2000) (discussing the use of Certificates of Confidentiality for nursing research); Patricia A. Carney et al., Current Medicolegal and Confidentiality Issues in Large, Multicenter Research Programs, 52 AM. J. EPIDEMIOLOGY 371, 373-74 (2000) (focusing on Certificates of Confidentiality use in health care settings). 
which are documented in a consent form. ${ }^{2}$ These promises of confidentiality typically include a promise to restrict access to the data and not to publish individually identifying information. ${ }^{3}$

The legal interests of others, however, can threaten researchers' promises of confidentiality if they seek access to the data through subpoena. For example, there recently was a high profile subpoena for research data more broadly: In 2010, the Virginia state attorney general subpoenaed research data from a prominent climate researcher, formerly from the University of Virginia, following release of emails concerning data on global warming, to determine whether the professor "violated Virginia's fraud laws in seeking state funding for research."4 In its petition seeking to block the subpoena, the University of Virginia suggested the subpoena constituted harassment that threatened to chill research on climate change. ${ }^{5}$ A state judge held that the attorney general failed to present sufficient evidence of fraud and did not have the authority to investigate fraud in federal grants. ${ }^{6}$ The attorney general then appealed to the Virginia Supreme Court, which has agreed to hear the case. ${ }^{7}$ Around the same time, Arizona's Superintendent of Pub-

2. Wolf \& Lo, supra note 1 , at 5 (explaining the obligations stem from the ethical principles of beneficence, which require researchers to minimize risks, and respect for persons); see also 45 C.F.R. § 46.111(a)(1), (a)(7) (2005) (containing the principles which form the foundation for the Common Rule, which explicitly obligates researchers to minimize risk and, "when appropriate," to maintain confidentiality of data and the privacy of subjects).

3. Wolf \& Lo, supra note 1 , at 5.

4. Sindya N. Bhanoo, University of Virginia Asks Judge to Block Subpoena, GREEN BLOG (May 28, 2010, 5:03 PM), http://green.blogs.nytimes.com/2010/05/28/quash-the-subpoena-u-va-urges/; see also Scott Jaschik, Another Subpoena for Research, INSIDE HIGHER ED (Aug. 13, 2010, 3:00 AM), http://www.insidehighered.com/news/2010/08/13/arizona. Note that some of the examples in this paragraph do not involves human subjects research data, but they are useful in demonstrating the wide range of potential litigation uses for research data and how that can place confidential human subjects research data at risk. They also point to some of the strategies lawyers have used in seeking to protect the data. (This caveat applies to more than the first example.).

5. Bhanoo, supra note 4; see also Jaschik, supra note 4.

6. John Collins Rudolf, Hearing Is Set in Climate Fraud Case, GREEN BLOG (Mar. 12, 2011, 9:00 AM), http://green.blogs.nytimes.com/2011/03/12/ hearing-is-set-in-climate-fraud-case/.

7. Id.; Brian McNeill, Judge Sides with UVA in Climate Case, Dismissing Cuccinelli Demands, DAILY PROGRESS http://www.dailyprogress.com/news/2010/aug/30/11/judge-sides-uva-climate- 
lic Instruction sought raw data from University of Arizona and Arizona State University researchers who conducted research on education of English-language learners (ELL) in Arizona. ${ }^{8}$ The Superintendent sought to use the data to challenge conclusions reached by the researchers who were acting as expert witnesses in a federal suit concerning Arizona's approach to ELL education. ${ }^{9}$ A judge ordered the universities to reveal the names of the schools that participated in the studies, but not the individual teachers and students. ${ }^{10}$ In 2011, the US Government issued a subpoena on behalf of the United Kingdom for data from a Boston College oral history project on the "Troubles" in Northern Ireland.11 It was understood that authorities intended to use the data for criminal prosecutions. ${ }^{12}$ Such use would violate the promises researchers made to research participants that their data would be kept confidential until they died. ${ }^{13}$ Furthermore, researchers studying the Deepwater Horizon oil disaster and responses to it, with its attendant litigation, anticipate that their research will be subpoenaed. 14

case-dismissing-cuccinelli-ar-479678/ (last updated Aug. 30, 2010, 12:33 PM).

8. Jaschik, supra note 4; Mary Ann Zehr, Arizona Subpoena Seeks Researchers' ELL Data, EDUC. WK. (Aug. 12, 2010), www.edweek.org/ew/ articles/2010/08/12/01arizona.h30.html.

9. Jaschik, supra note 4; Zehr, supra note 8.

10. David Glenn, In Research Dispute, Judge Orders Arizona Universities to Disclose Schools' Names, Chron. Higher EDUC. (Aug. 23, 2010), http://chronicle.com/blogs/ticker/in-research-dispute-judge-orders-arizonauniversities-to-disclose-schools-names/26397; Court Order at 2, Flores v. Arizona, No. CV 92-596-TUC-RCC (D. Ariz. Aug. 19, 2010) (“[I]ndividual research participants were promised their anonymity would be preserved and the Court intends to honor that promise.").

11. Jim Dwyer, Secret Archive of Ulster Troubles Faces Subpoena, N.Y. TIMES, May 13, 2011, at A1; see also Scott Jaschik, Oral History, Unprotected, INSIDE HigheR ED (July 5, 2011, 3:00 AM), http://www.insidehighered.com/news/2011/07/05/federal_government_question s_confidentiality_of_oral_history; Ben Wieder, Boston College Fights Subpoena for Confidential Interviews on Irish Violence, CHRON. HIGHER EDUC. (June 8, 2011), http://chronicle.com/article/Boston-College-Fights-Subpoena/127851/.

12. Dwyer, supra note 11.

13. Wieder, supra note 11.

14. Richard Knox, Legal Battles Over Oil Spill Could Foul Reearch on Health Effects, SHOTS: NPR's HEALTH BLOG (June 23, 2010, 11:57 AM), http://www.npr.org/blogs/health/2010/06/23/128030107/legal-battles-over-gulfoil-spill-could-foul-research-on-health-effects; Stu Hutson, Fight for Subject Confidentiality Threatens Disaster Research, 16 NATURE MED. 833, 833 (2010); INST. OF MED., REVIEW OF THE PROPOSAL FOR THE GULF LONG-TERM FOLLOWUP STUDY: HighlightS FROM THE SEPTEMBER 2010 WORKSHOP 13 (Lynn 
As these cases demonstrate, research data may be put to a wide range of uses in litigation. In some cases, the subject of the litigation is tightly connected to the research questions, and litigants' interest in the data is not surprising. Researchers conducting tobacco-related research or research on occupational or other environmental exposures, for example, are relatively frequent targets of subpoenas to support or defend against claims or to challenge the findings of experts or undermine their credibility. ${ }^{15}$ Similarly, those conducting research on controversial topics, including those involving criminal activity, should not be surprised that their data may be considered useful in building cases. ${ }^{16}$ In other cases, litigants' interest in the

Goldman et al. eds., 2010), available at http://www.ncbi.nlm.nih.gov/books/ NBK50908/pdf/TOC.pdf (explaining that treatment of research data from the Exxon Valdez oil spill in Alaska provides precedent to release of data for the Deepwater Horizon spill); see also Eliot Marshall, Court Orders 'Sharing' of Data, 261 SCI. 284, 284-86 (1993).

15. See, e.g., Farnsworth v. Procter \& Gamble Co., 758 F.2d 1545, 1546-47 (1985) (detailing that industry sought data from Toxic Shock Syndrome studies for use in products liability action); Deitchman v. E.R. Squibb \& Sons, Inc., 740 F.2d 556, 557-58 (1984) (detailing that industry sought data from cancer registry in connection with products liability action relating to use of diethylstilbestrol (DES)); see also, Confidentiality Order Re WHI Study Data, In re PremPro Products Liability Litigation, No. 4:03-CV-01507-WRW (E.D. Ark. Feb. 1, 2005); Order Re: Motion to Quash Subpoenas Re Yale Study's Hospital Records, In re Phenylpropanolamine Products Liability Litigation, No. 1407 (W.D. Wash. Aug. 19, 2002). When data are sought to defend against a claim, the requester may want identifiable data, which is less relevant to requests intended to challenge the research findings. Some have reported that the tobacco industry used this tactic against journalists, as well as researchers. See Andrew A Skolnick, Burning Mad Tobacco Industry Turns Heat on Major News Media, SCIENCEWRITERS: NEWSL. NAT'L ASS'N SCI. WRITERS (Nat'l Assoc. of Sci. Writers, Berkeley, Cal.), Summer 1994, available at http://www.aaskolnick.com/naswtob.htm; Marcia Barinaga, Who Controls a Researcher's Files, 256 SCI. 1620, 1620-21 (1992). In some cases, the impact on researchers has been extreme. In one case, a Georgia researcher twice was successful in protecting his research data from disclosure to the tobacco industry, but the industry then sought the records from his institution, a state medical college, as public documents. The researcher resigned from the school after it failed to support his efforts to protect the documents. Skolnick, supra note 15. In 2011, the Georgia legislature revised its evidence law, effective in 2013, to include protections for researchers' raw data from subpoena. GA. CODE ANN. § 24-122 (2011).

16. Jaschik, supra note 8 (referring to Boston College Northern Ireland oral history project as one prime example). Another well-known example is that of sociologist Rick Scarce, who conducted research on the Animal Liberation Front, which subsequently claimed responsibility for a break-in at Washington State University research labs. Prosecutors sought his data for use in 
research data may relate to individual participants, rather than the research in question, and may not be anticipated. ${ }^{17}$

When the data they collect could place research participants at risk from disclosure, researchers need to take steps to minimize that risk. ${ }^{18}$ Certificates of Confidentiality (Certificates) are an important tool for protecting individually identifiable, sensitive research data from compelled disclosure. ${ }^{19}$ As described more fully below, federal law authorizes the Secretary of Health and Human Services (HHS) and the Attorney General in the Department of Justice (DOJ) to issue Certificates to protect such data, whether or not the research is federally funded. ${ }^{20}$ The scope of the protection, according to the authorization statutes, is large: "[Persons granted a Certificate] may not be compelled in any Federal, State, or local civil, criminal, administrative, legislative, or other proceedings to identify such individuals." 21 However, questions persist in the research community about the strength of Certificate protections, and the evidence on which to judge the strength is scant. ${ }^{22}$ The

the criminal case. When Scarce refused to provide it, he was placed in jail for contempt of court. Marshall, supra note 14, at 285. See also JONI N. GRAY ET AL., ETHICAL AND LEGAL ISSUES IN AIDS RESEARCH 13-17, 63-68 (1995) (explaining that HIV researchers have long been cognizant that the research they conduct could put their participants at risk of criminal prosecution based on their sexual or drug-using behaviors).

17. Leslie E. Wolf et al., Certificates of Confidentiality: Legal Counsels' Experiences with and Perspectives on Legal Demands for Research Data, $7 \mathrm{~J}$. EMPIRICAL RES. HUM. RES. ETHICS 1 (2012) (providing an example that of demographic data, including income, might be sought for custody and child support purposes).

18. See Wolf \& Lo, supra note 1 , at 5 .

19. See infra Part II. It is important to recognize that the projects we have described in this introduction may not all be eligible for a Certificate. For example, although a project need not be federally funded to receive a Certificate, it does need to be within the NIH "mission." FAQs on Certificates, supra note 1. Accordingly, the Boston College oral history project may not qualify for a Certificate because the topic falls outside the NIH mission. Whether the oral history is considered "research" as defined under the federal regulations could also affect whether the project was eligible for a Certificate. Donald A. Ritchie \& Linda Shopes, Oral History Excluded from IRB Review, ORAL HIST. ASS'N NEWSL. (Oral History Assoc., Carlisle, Pa.), Winter 2003, at 1, available at http://www.oralhistory.org/wp-content/uploads/2008/10/opoha199.pdf; see also FAQs of Certificates, supra note 1.

20. FAQs on Certificates, supra note 1.

21. 42 U.S.C. $\S 241(d)(2006)$.

22. Laura M. Beskow et al., Institutional Review Boards' Use and Understanding of Certificates of Confidentiality, PLOS ONE, Sept. 4, 2012, at 1, 1-2 [hereinafter Institutional Review Board]. 
most frequently cited case that involved a Certificate, the 1973 case People v. Newman, suggests that Certificates are strongly protective of data. ${ }^{23}$ But a 2006 North Carolina case, North Carolina $v$. Bradley, raises questions about that protection. ${ }^{24}$

In this article, we undertake an examination of Certificates and related statutory protections available to researchers to enhance understanding of Certificates and how to strengthen the Certificate's protections. We begin, in Part I, by describing researchers' obligations to protect the confidentiality of data they collect. In Part II, we explore the legislative and regulatory history, and the case law-both reported and unreportedinterpreting Certificates to understand the strengths and weaknesses of Certificates. In Part III, we analyze other statutes and regulations that provide similarly broad confidentiality protections for research data and the cases that interpret them and compare them to Certificates. In Part IV, we briefly examine other legal strategies available for protecting research data. Finally, in Part V, we make recommendations for how to strengthen protection of sensitive research data based on our legal analyses.

\section{RESEARCHERS' CONFIDENTIALITY OBLIGATIONS}

That researchers have an obligation to protect the confidentiality of information that participants share with them is widely acknowledged. ${ }^{25}$ The federal regulations governing hu-

23. People v. Newman, 298 N.E.2d 651, 652-57 (N.Y. 1973). However, the court's analysis focused on an apparent conflict between the 1970 Act authorizing Certificates and a 1972 act, rather than on the Certificate protection itself, even though the Court determined that the clinic director did not need to produce the data. Id. But cf. Laura M. Beskow et al., Certificates of Confidentiality and Compelled Disclosure of Data, 322 SCI. 1054, 1054-55 (2008) [hereinafter Compelled Disclosure of Data] (examining a case that indicates "the protection Certificates offer is uncertain"). See also infra Part II.C.

24. North Carolina v. Bradley, 634 S.E.2d 258, 261-63 (N.C. 2006). The trial court permitted access to data to assist with the appeal. Although the appellate court ultimately denied access to the data, it did not consider the Certificate in doing so. Id. (citations omitted); see also infra Part II.C.

25. See Basic IRB Review, in INSTITUTIONAL REVIEW BOARD GUIDEBOOK (1993), available at http://www.hhs.gov/ohrp/archive/irb/irb_guidebook.htm ("IRBs should determine the adequacy of the provisions to protect the privacy of subjects and to maintain the confidentiality of the data and, where the subjects are likely to be members of a vulnerable population (e.g., mentally disabled), determine that appropriate additional safeguards are in place to 
man subjects research (hereafter "the federal regulations" or the "Common Rule") 26 impose an obligation on institutional review boards (IRBs), which review and approve research studies, to ensure that "there are adequate provisions to protect the privacy of subjects and to maintain the confidentiality of data" before approving a study. ${ }^{27}$ In addition, the federal regulations require that "risks to subjects are minimized." 28 These two provisions of the federal regulations thus impose an obligation on researchers to take steps to protect confidentiality, at least when the study methods and topic make confidentiality an issue. The importance of preserving confidentiality is also implied in other parts of the federal regulations. For example, whether otherwise confidential information, such as medical records, used in research could be linked back to an individual is an important consideration in determining whether the research is subject to the federal regulations and requires IRB oversight. ${ }^{29}$ Finally, because research often uses information

protect the rights and welfare of these subjects."); see also Wolf \& Lo, supra note 2 (describing the legal and ethical bases for the obligation to maintain confidentiality).

26. 45 C.F.R. § 46.101 (2011). The HHS regulations governing the conduct of research involving human subjects research apply to research that is funded through that department, including the National Institutes of Health and the Centers for Disease Control and Prevention (CDC), which together support the greatest amount of federally funded research. Another seventeen agencies have agreed to abide by these regulations for their research. Accordingly, the HHS regulations are referred to as the "Common Rule." Federal Policy for the Protection of Human Subjects ('Common Rule'), HHS.GOv, http://www.hhs.gov/ ohrp/humansubjects/commonrule/index.html (last visited Nov. 5, 2012); see also 21 C.F.R. $\S \S 50,56$ (2011) (promulgating regulations in the Food and Drug Administration (FDA), which are substantially similar to the Common Rule). For a comparison between these regulations, see U. S. Food and Drug Administration, Comparison of FDA and HHS Human Subjects Protection Regulations,

FDA.GOV, http://www.fda.gov/ScienceResearch/SpecialTopics/RunningClinicalTrials/educ ationalmaterials/ucm112910.htm (last updated Mar. 10, 2009).

27. Protection of Human Subjects 45 C.F.R. $§ 46.111(\mathrm{a})(7)$ (“(7) When appropriate, there are adequate provisions to protect the privacy of subjects and to maintain the confidentiality of data.").

28. Protection of Human Subjects, 45 C.F.R. § 46.111(a)(1) (“(a) In order to approve research covered by this policy the IRB shall determine that all of the following requirements are satisfied: (1) Risks to subjects are minimized: (i) By using procedures which are consistent with sound research design and which do not unnecessarily expose subjects to risk, and (ii) whenever appropriate, by using procedures already being performed on the subjects for diagnostic or treatment purposes.").

29. Protection of Human Subjects, 45 C.F.R. § 46.101(b)(4) (“(b) Unless otherwise required by department or agency heads, research activities in 
that is legally protected as confidential, such as medical or education records, there are often existing expectations about maintaining data confidentiality. ${ }^{30}$

There are a number of ways that researchers may protect the confidentiality of research participants and their data. For example, researchers may collect data on sensitive information, such as substance abuse, other criminal activity, or sexual behaviors, through anonymous surveys, thus ensuring that the information cannot be linked back to an individual. ${ }^{31}$ Or if data needs to be linked, researchers may code the data so that it is not immediately identifiable. In such cases, the researchers typically limit access to the key of the coding system and take steps to secure the data through physical means (e.g., locked cabinets) or electronic means (e.g., password protection). ${ }^{32}$ The researchers also will often destroy the key once it is no longer needed as an added protection. ${ }^{33}$

Even without the regulatory requirements, many researchers would likely take steps to protect participants' confidentiality on purely pragmatic grounds; without assurances that researchers will protect their information, many people would not participate in research on sensitive topics. ${ }^{34}$

\section{CERTIFICATES OF CONFIDENTIALITY}

As described below, Certificates were originally authorized in 1970 for research involving drug use. Since the original authorization, the scope of Certificates has been expanded considerably, so that it now covers all types of research methods and any research topic where breach of confidentiality of individual

which the only involvement of human subjects will be in one or more of the following categories are exempt from this policy:... (4) Research, involving the collection or study of existing data, documents, records, pathological specimens, or diagnostic specimens, if these sources are publicly available or if the information is recorded by the investigator in such a manner that subjects cannot be identified, directly or through identifiers linked to the subjects.").

30. See, e.g., Basic IRB Review, supra note 25 (discussing expectations of privacy and confidentiality in biomedical research compared to so$\mathrm{cial} / \mathrm{behavioral} \mathrm{research).}$

31. Nelson P. Miller, Subpoenas in Academia: Controlling Disclosure, 17 J. C. \& U. L. 1, 8 (1990).

32. See Wolf \& Lo, supra note 1, at 4 .

33. See Basic IRB Review, supra note 25 (regarding "Privacy and Confidentiality.").

34. See Wolf \& Lo, supra note 1 , at 5. 
information could harm that individual, whether physically, emotionally, socially, or economically.

\section{A. LEGISLATIVE AUTHORITY}

Need for Protection. The protections afforded by Certificates were originally authorized as part of the Comprehensive Drug Abuse Prevention and Control Act of 1970 (1970 Act). ${ }^{35}$ Responding in part to the drug problems among returning Vietnam War veterans, the overall purpose of the 1970 Act was "to deal in a comprehensive fashion with the growing menace of drug abuse," 36 and to address punishment and rehabilitation of drug users, as well as to obtain research needed for understanding drug use in the United States. Confidentiality protections were needed, as the House Report recognizes, "[s]ince drug abuse involves illegal activities under both State and Federal law, [and therefore,] reliable statistics cannot be obtained on the actual extent of drug use" without such protections. ${ }^{37}$

The enactment of the 1970 Act was the culmination of efforts over several years to reform federal laws regarding drug use and control. ${ }^{38}$ In support of those efforts, members of Congress heard testimony describing the critical need for research on drugs and drug abuse to develop appropriate treatments, ${ }^{39}$ as well as the challenges in conducting such research because it involved illegal activity. Disclosure of data could place the participants at legal risk. ${ }^{40}$ As one researcher explained, Congress

35. Comprehensive Drug Abuse Prevention and Control Act of 1970, Pub. L. No. 91-513, 84 Stat. 1236, 1241 (1970).

36. H.R. REP. No. 91-1444 (1970), reprinted in 1970 U.S.C.C.A.N. 4566, 4567.

37. H.R. REP. No. 91-1444 (1970), reprinted in 1970 U.S.C.C.A.N. 4566, 4572 .

38. See Robert L. Bogomolny Et AL., A HANDBoOK ON THE 1970 Federal Drug ACt: Shifting the Perspective (Charles C. Thomas ed., 1975) (detailing the history of the passage of the Act).

39. Comprehensive Narcotic Addiction and Drug Abuse Care and Control Act of 1969: Hearings on S. 2608, S. 2637, S. 1816, S. 1895, H.R. 11701, and H.R. 10342 Before the Special Subcomm. on Alcohol and Narcotics of the S. Comm. on Labor and Public Welfare, 91st Cong. 93-97 (1969) [hereinafter Comprehensive Narcotic Addiction Hearings] (statement of Dr. Helen Nowlis) ("Now, one of the big problems here is the complete lack of understanding of what drugs are and how they act.... So what we need is not research in the laboratory. We need research in the field. We need to be able to study the people who choose to use drugs, why they choose to use them, the pattern of use.").

40. Id. at 98. See also Federal Drug Abuse and Dependence Prevention, Treatment, and Rehabilitation Act of 1970: Hearings on S. 3562, S. 3246, and 
wanted researchers "to study people under conditions where they must admit they have committed a felony." 41 In order to succeed with such research, researchers "had to guarantee confidentiality. [They] had to guarantee it to the point where [they], between [researcher and subject], agreed that [they] would face contempt rather than betray a confidence." 42

The researchers' concerns were not merely theoretical. Researchers described to Congress their experiences with law enforcement interference in ongoing research projects, negatively affecting morale and motivation to continue:

Our studies involve the use of heroin in drug-dependent volunteer subjects. After a few months of study, our work was brought to the attention of the police of New York City and the commissioner of the investigation (1966, Mr. Arnold Fraiman). Rather than approach the problem in a civil fashion, his office exercised their police authority to issue subpenas [sic] and arrest, to insist that we appear to answer the charges of illegal use of controlled drugs. ${ }^{43}$

To continue their research, researchers had to make private agreements with local law enforcement officers. ${ }^{44}$ As they expressed to Congress, the researchers supported the confidentiality provisions in the new law, which they hoped would eradicate these problems. ${ }^{45}$ For example, one researcher testified:

A provision of S. 1895 is strongly recommended for this bill: to authorize researchers to withhold the names of subjects and to possess and distribute drugs where required for research without fear of Federal or State prosecution. This feature will permit field investigators to get information the public really wants without turning research investigators into informers (or criminals if they ethically insist on withhold-

S. 2785 Before the Special Subcomm. on Alcohol and Narcotics of the S. Comm. on Labor and Public Welfare, 91st Cong. 168 (1970) [hereinafter Federal Drug Abuse Hearings] (statement of Dr. Max Fink) ("[R] esearch in drug abuse and drug dependence is encumbered by the administration of confusing and restrictive laws, by police attitudes of repression, [and] by irrational fears of involvement with the laws governing controlled substances."); Narcotics Legislation: Hearings on S. 1895, S. 2590, H.R. 10019, and S. 2637 Before the Subcomm. to Investigate Juvenile Delinquency, S. Comm. on the Judiciary, 91st Cong. 315-321 (1969) [hereinafter Narcotics Legislation Hearings] (statement of Dr. Henry Brill) ("The fear of such disclosure and of prosecution, especially on State and local levels, has served to hamper needed research in the past.").

41. Comprehensive Narcotic Addiction Hearings, supra note 39, at 98.

42. $I d$.

43. Federal Drug Abuse Hearings, supra note 40, at 169.

44. Id. at $172-73$.

45. Id. at 172 . 
ing personal information.) $)^{46}$

Lawyers and judges also expressed their agreement with the confidentiality provision. Describing the provision as "one of the most important things" in the bill, one judge expressed his support of the bill based on discussions with "doctors who would like to enter the field of research but they feel the constant hot breath of some ardent law enforcer is upon their necks and they simply will not go into research at all." 47 Lawyer Lawrence Speiser, the Director of the Washington Office of the American Civil Liberties Union expressed his support as follows:

There is an obviously sincere attempt in those bills, those provisions [discussing confidentiality], to prevent disclosure of the names of the addicts and to prevent any individual who has access to it from being required to give the name of those individuals, because obviously this information could be utilized in a criminal prosecution. ${ }^{48}$

Congress responded to these calls of support by including the confidentiality provision within many different bill versions leading to the Act. ${ }^{49}$ Though the language of the confidentiality provision varied from bill to bill, each bill recognized the necessity of maintaining confidentiality of human subjects participating in drug research. 50

Statutory Protection Language. The 1970 legislation authorizing Certificates provided the following:

The Secretary may authorize persons engaged in research on the use and effect of drugs to protect the privacy of individuals who are the subject of such research by withholding from all persons not connected with the conduct of such research the names or other identifying characteristics of such individuals. Persons so authorized to protect the privacy of such individuals may not be compelled in any Federal, State, or local civil, criminal, administrative, legislative, or other pro-

46. Comprehensive Narcotic Addiction Hearings, supra note 39, at 385 (statement of Daniel Freedman).

47. Narcotics Legislation Hearings, supra note 40, at 304 (statement of J. Samuel T. Tedesco).

48. Drug Abuse Control Amendments, 1970: Hearing on S. 3246, H.R. 11701 and Related Bills Before the Subcomm. on Public Health and Welfare, H. Comm. on Interstate and Foreign Commerce, 91st Cong. 299 (1970) (statement of Lawrence Speiser); see also Comprehensive Narcotic Addiction Hearings, supra note 39, at 404 (statement of Neil Chayet) ("[I]t is unfortunate that researchers in this day and age have to secure attorneys to help them with their research, which happens often, and is going on right now.").

49. Comprehensive Narcotic Addiction Hearings, supra note 39, at 123 (comparing five different House and Senate drug bills with a specific comparison of provisions for drug abuse research).

50. Id. 
ceedings to identify such individuals. ${ }^{51}$

As described in the House Report of the 1970 Act, this new section grants

the Secretary of Health, Education, and Welfare a much needed authority to protect the privacy of drug research subjects by nondisclosure of identification data of such individuals. It enables the research, when authorized by the Secretary, to assure research subjects complete anonymity, with immunity from prosecution for withholding this identifying information. ${ }^{52}$

The original authorizing statute has been amended several times. ${ }^{53}$ As part of the Comprehensive Alcohol Abuse and Alcoholism Prevention, Treatment, and Rehabilitation Act Amendments of 1974, the scope of the protections afforded by 42 U.S.C. $§ 242$ a was broadened from research on "the use and effect of drugs" to research on "mental health, including research on the use and effect of alcohol and other psychoactive drugs." 54 In 1988, as part of the Health Omnibus Programs Extension of 1988, a wide-ranging law that addressed numerous healthrelated programs, several amendments were made to the authorizing statute. ${ }^{55}$ First, the law re-designated sections of the Public Health Service Act, including locating the Certificate authorization language in its current codified location, 42 U.S.C. $\S 241(d) .56$ In addition, the range of research protected was again broadened to include biomedical, behavioral, clinical or other research, which specifically includes research on mental health and substance abuse, rather than limiting the protections to mental health and substance abuse research. ${ }^{57}$ As a result, the full text of the current authorizing statute, 42 U.S.C.

51. Comprehensive Drug Abuse Prevention and Control Act of 1970, Pub. L. No. 91-513, 84 Stat. 1236, 1241 (1970).

52. H.R. REP. No. 91-1444 (1970), reprinted in 1970 U.S.C.C.A.N. 4566, 4594-95 (emphasis added). The Department of Health, Education and Welfare (HEW) was established April 11, 1953. Historical Highlights, HHS.GOV, http://www.hhs.gov/about/hhshist.html (last visited Nov. 6, 2012). In 1979, the Department of Education became a separate agency, and HEW became the Department of Health and Human Services on May 4, 1980. Id.

53. Our review of legislative history did not reveal the reasons for the changes.

54. Comprehensive Alcohol Abuse and Alcoholism Prevention, Treatment, and Rehabilitation Act Amendments of 1974, Pub. L. 93-282, 88 Stat. 125, 132-33 (1974).

55. Health Omnibus Programs Extension of 1988, Pub. L. 100-607, 102 Stat. 3048 (1988).

56. Id. at 3062 .

57. $I d$. 
$\S 241(\mathrm{~d})$, which is entitled "Protection of privacy of individuals who are research subjects," provides:

The Secretary [of Health and Human Services] may authorize persons engaged in biomedical, behavioral, clinical or other research (including research on mental health, including research on the use and effect of alcohol and other psychoactive drugs) to protect the privacy of individuals who are the subject of such research by withholding from all persons not connected with the conduct of such research the names or other identifying characteristics of such individuals. Persons so authorized to protect the privacy of such individuals may not be compelled in any Federal, State, or local civil, criminal, administrative, legislative, or other proceedings to identify such individuals. 58

The 1970 act also granted the Attorney General similar authority:

The Attorney General may authorize persons engaged in research [directly related to enforcement of the laws under his jurisdiction concerning drugs or other substances which are or may be subject to control under this title] to withhold the names and other identifying characteristics of persons who are the subjects of such research. Persons who obtain this authorization may not be compelled in any Federal, State, or local civil, criminal, administrative, legislative, or other proceeding to identify the subjects of research for which such authorization was obtained. ${ }^{59}$

Although this statute has been amended since passage, none of the changes have affected the Certificate authority. ${ }^{60}$ Given the DOJ's overall mission and the statute's specific link to educational and research programs related to drug laws, it is not surprising that the scope of the DOJ Certificate statute was not broadened as was the HHS Certificate. In practice, the DOJ appears to rely on the protections afforded under 42 U.S.C. $\S 3789 \mathrm{~g}$ for research it oversees or funds, as described more fully below. 61

\section{B. REGULATORY AUTHORITY}

While the authority for Certificates' confidentiality protections lies in the statutes, ${ }^{62}$ it is the HHS regulations that speci-

58. 42 U.S.C. $§ 241(d)(2006)$.

59. Compare Comprehensive Drug Abuse Prevention and Control Act of 1970, Pub. L. 91-513, 84 Stat. 1236, 1271 (1970), with 21 U.S.C. § 872(c) (2006).

60. See 21 U.S.C. $\S 872$ (referring to the cited history).

61. 42 U.S.C. $§ 3789$ g. See also FAQs on Certificates, supra note 1 (stating when such DOJ's protections apply, the NIH advises against also applying for a Certificate through the NIH).

62. 42 U.S.C. $§ 241(d) ; 21$ U.S.C. $§ 872(c)$. 
fy the Certificates' form. 63 The regulations define the "identifying characteristics" that are protected by the Certificate as "the name, address, any identifying number, fingerprints, voiceprints, photographs or any other item or combination of data about a research subject which could reasonably lead directly or indirectly by reference to other information to identification of that research subject."64

The regulations also clearly give authority to the National Institutes of Health (NIH) to issue Certificates upon application, regardless of whether the research project is funded by the federal government.65 42 C.F.R. $§ 2$ a.4 specifies the content of an application 66 and the information that must be disclosed to research participants about the Certificate. ${ }^{67}$ The required information includes that

(1) A Confidentiality Certificate has been issued; (2) The persons authorized by the Confidentiality Certificate to protect the identity of research subjects may not be compelled to identify research subjects in any civil, criminal, administrative, legislative, or other proceedings whether Federal, State, or local; (3) If any of the following conditions exist the Confidentiality Certificate does not authorize any person to which it applies to refuse to reveal identifying information concerning research subjects: (i) The subject consents in writing to disclosure of identifying information, (ii) Release is required by the Federal Food, Drug, and Cosmetic Act (21 U.S.C. 301) or regulations promulgated thereunder (title 21, Code of Federal Regulations), or (iii) Authorized personnel of DHHS request identifying information for audit or program evaluation of a research project funded by DHHS or for investigation of DHHS grantees or contractors and their employees or agents carrying out such a project. (See $\S 2 \mathrm{a} .7(\mathrm{~b})$ ); (4) The Confidentiality Certificate does not govern the voluntary disclosure of identifying characteristics of research subjects; (5) The Confidentiality Certificate does not represent an endorsement of the research project by the Secretary. 68

63. See Protection of Identity-Research Subjects, 42 C.F.R. § 2a (2011). These regulations have been unchanged since 1979 and, thus, do not reflect the full scope of the research that is eligible for protection.

64. 42 C.F.R. $\S 2 \mathrm{a} .2(\mathrm{~g})$.

65. 42 C.F.R. $\S \S 2$ a.1, 2 a.3.

66. See 42 C.F.R. $§ 2$ a.4. The application must include a "specific request, signed by the individual primarily responsible for the conduct of the research, for authority to withhold the names and other identifying characteristics of the research subjects and the reasons supporting such request." 42 C.F.R. $\S$ 2a.4(f).

67. 42 C.F.R. $\S 2 a .4(j)$.

68. 42 C.F.R. $\S 2$ a.4(j)(1)-(5). The disclosure mirrors the 42 C.F.R. § 2a.7 provisions concerning the effect of the Certificate. 


\section{Reported CAses Involving CeRtificates}

There are few reported cases that have interpreted Certificates and the protection provided by them.69 This is not surprising given that Certificates protect against compelled discovery. For both procedural and practical reasons, few discovery decisions are appealed and, thus, give rise to reported decisions. ${ }^{70}$ This section analyzes the few cases that address Certificates and their implications.

People v. Newman. ${ }^{71}$ If people are aware of any court decisions regarding Certificates, it is People v. Newman, the first case to address the confidentiality provision introduced in the 1970 Act. The facts tell a compelling story: because he had a Certificate that protected the records, the director of a methadone clinic was not required to provide clinic records (photographs) that were subpoenaed for use in identifying a murderer. ${ }^{72}$ The legal story, however, focused more on the conflict between two statutes than the scope of the Certificate's protections. ${ }^{73}$

In Newman, a witness to a June 7, 1972 murder informed police that she believed she had seen the murderer prior to the shooting in the waiting room of a methadone maintenance treatment clinic where she was also a patient. ${ }^{74}$ Based on this information, a grand jury subpoena was served on Dr. Robert Newman, the Director of the New York City Methadone Maintenance Treatment Program. ${ }^{75}$ The subpoena required Dr. Newman to produce "photographs of Negro males between the ages of 21 and 35 who were patients at Unit Two of Delafield in 1972, prior to June 7."76 In response, Dr. Newman moved to

69. To identify reported cases involving Certificates, we conducted legal research in both Lexis and Westlaw using multiple strategies, including Shepardizing each of the reported cases of which we were aware and looking at any cases identified through that process, conducting searches on the statutory authority and the regulatory authority, and conducting searches for the keywords "Certificate" and "confidentiality."

70. See 15B Charles Alan Wright \& ARthur R. Miller, Federal PRACTICE AND PROCEDURE §3914.23 (2d ed. 2012) (describing the lack of finality of most discovery orders and, thus, the inability to get judicial review of them).

71. People v. Newman, 298 N.E.2d 651 (N.Y. 1973) .

72. Id. at $652-53$.

73. Compelled Disclosure of Data, supra note 23.

74. Newman, 298 N.E.2d at 653.

75. Id.

76. Id. 
quash the subpoena on the grounds that the production was prohibited under federal law (which authorized the Certificate) and New York law (which protected the confidentiality of the doctor-patient relationship). 77

The trial court denied Dr. Newman's motion and, when he still refused to produce the photographs, found Dr. Newman to be in contempt of court and sentenced him to thirty days in jail. ${ }^{78}$ Dr. Newman promptly appealed to the Appellate Division. ${ }^{79}$ While acknowledging the ethical norm concerning the confidentiality of doctor-patient relationship, the Appellate Division affirmed the contempt finding. ${ }^{80}$ However, the Appellate Division modified the subpoena order to add "appropriate safeguards against unnecessary disclosure" by requiring "the witness [to] view the photos under supervision of defendant Commissioner or someone designated by him, and that none of the pictures may be exhibited to police or prosecutor except that one which she may identify as the person sought." 81 Dr. Newman appealed to the New York Court of Appeals on the same grounds. ${ }^{82}$

The Court of Appeals focused its analysis on Dr. Newman's claim that the photographs were protected by the 1970 Act. ${ }^{83}$ In support of this argument, Dr. Newman produced a letter from the Attorney General to himself, dated November 8, 1972, which granted absolute confidentiality to patient records in the New York Methadone Maintenance Treatment Program. ${ }^{84}$ The letter stated:

77. Id. 1972).

78. Id.; see also People v. Newman, 336 N.Y.S.2d 127, 129 (App. Div.

79. Newman, 298 N.E.2d at 653.

80. Newman, 336 N.Y.S.2d at 129.

81. Id.

82. Newman, 298 N.E.2d at 653.

83. Id. at 654 . Dr. Newman also claimed state law physician-patient privilege protected the photographs, a claim the Court quickly rejected. Relying on the language from the statute, the Court found that the photographs had not been "acquired in attending a patient in a professional capacity" by Dr. Newman. Rather, the photographs had been collected by the staff at the clinic to "prevent unregistered patients from obtaining methadone and registered patients from obtaining the wrong dosage through administrative errors in identification." Thus, the photographs served "solely... a medical management function" and could not be "deemed privileged confidential information within the sense of the statute." Id. at 653.

84. Id. at 655 . 
I hereby authorize you to withhold the names and other identifying characters of persons who are the subjects of research conducted pursuant to and in conformity with this research project. You may not be compelled in any Federal, State, or local civil, criminal, administrative, legislative, or other proceeding to identify the subjects of such research. 85

The New York District Attorney contended, however, that under the Drug Abuse Office and Treatment Act of 1972 (1972 Act), the "directors of methadone maintenance programs may be compelled to produce those records upon court order." 86 Thus the Court needed to determine "whether the 1972 Act repealed the 1970 Act insofar as confidentiality of a patient's record is concerned." 87

Relying on an amicus curiae brief filed for the United States by the Department of Health, Education, and Welfare along with the Special Action Office for Drug Abuse Prevention in support of Dr. Newman's position, the Court turned its attention to the interpretative regulations put forth by the Special Action Office in the Federal Register, which dealt with the 1972 Act, but also discussed the 1970 Act. 88 The Court noted that the regulations "recited that the 1972 Act was not designed to repeal or amend the confidentiality provision of the 1970 Act." 89 Instead, the regulations specifically set out to avoid this interpretation:

Nothing in either the language or the legislative history of the Act indicates any intent on the part of Congress to amend the provisions of the 1970 Act or to reduce the protection which can be afforded under them. Since the language of section 408 permits, if it does not require, a construction which harmonizes with the 1970 Act, it clearly should not be construed to authorize a court order in derogation of any exercise of the authority of the Secretary of Health, Education, and Wel-

85. Id. at 655 n.5.

86. Id. at 654 . Unlike the absolute protections under the 1970 Act, 21 U.S.C. $§ 1175$ under the 1972 Act provided protection to

[r] ecords of the identity, diagnosis, prognosis, or treatment of any patient which are maintained in connection with the performance of any drug abuse prevention function conducted, regulated, or directly or indirectly assisted by any department or agency of the United States shall ... be confidential and be disclosed only for the purposes and under the circumstances expressly authorized under subsection (b) of this section,

where subsection (b) includes disclosure based upon a court order after a showing of good cause. 21 U.S.C. $§ 1175$ (1976).

87. Newman, 298 N.E.2d. at 654.

88. Id. at 655 .

89. Id. 
fare under section $242 \mathrm{a}$ (a) of title $42 .{ }^{90}$

Relying upon the Special Action Office's interpretations of the two statutes, the Court determined that the 1972 Act "did not ... affect the provision in the 1970 Act for absolute confidentiality in drug research programs." 91 The Court noted that the granting of absolute confidentiality in the 1970 Act was necessary to "ensure the success of drug research programs in which addict participants require anonymity." 92 In contrast, the Court stated that, because the 1972 Act "covered a wide range of programs and activities ('drug abuse prevention functions') in which absolute confidentiality was not regarded as a prerequisite to the successful operation of the programs," the confidentiality requirements were necessarily different from those in the 1970 Act. 93 The Court thus found that "the absolute confidentiality provision of the 1970 Act applie[d] to drug research programs, such as Dr. Newman's, where the success of the program depends upon the ability of the director to guarantee each patient that his participation will not be disclosed to anyone not connected with the program." 94 Accordingly, the Court held that Dr. Newman may not then be compelled to produce the photographs and could not be held in contempt for failure to do

90. Confidentiality of Drug Abuse Patient Records, 37 Fed. Reg. 24,636, 24,639 (Nov. 17, 1972).

91. Newman, 298 N.E.2d. at 656; see also Robert M. McNamara, Jr. \& Joyce R. Starr, Confidentiality of Narcotic Addict Treatment Records: A Legal and Statistical Analysis, 73 ColuM. L. REV. 1579, 1607 (1973) ("Judge Fuld, however, quoting extensively from the [Special Action Office for Drug Abuse Prevention] interpretative regulation, held that the 1970 Act confidentiality provisions were still in effect, unamended by the 1972 Act.”).

92. Newman, 298 N.E.2d at 655-56. Accord, State v. White, 363 A.2d 143, 151-52 (Conn. 1975) (distinguishing between the absolute confidentiality of the 1970 Act compared to the qualified confidentiality of the 1972 Act).

93. Newman, 298 N.E.2d at 656. Judge Breitel, writing in dissent, disagreed with the majority's reliance on the Special Action Office's interpretative regulations. Id. at 657-59 (Breitel, J., dissenting) ("The effect of the [1972] statute is to place in the court the sole power to disclose a patient's record after balancing the several interests involved. That is what it says. There are no qualifications. It does not give any primary or secondary role in the disclosure to the program officials or to supervisory administrators."). While the majority stressed the policy issue concerning the success of drug research programs, Judge Breitel honed in on the law enforcement aspect of the issue by concluding, "Even if ambiguous language were involved, one should hesitate to ascribe a meaning to it which may very well mean in this case that a murderer should go free." Id. at 659 (Breitel, J., dissenting).

94. Id. at 657 . 
so. ${ }^{95}$

People v. Still. ${ }^{96}$ Like Newman, People v. Still involved a subpoena served on a methadone maintenance clinic to produce records relating to a patient. ${ }^{97}$ The defendant, Still, was charged with criminal possession of methadone, a controlled substance. ${ }^{98}$ In his defense, Still asserted that he was in lawful possession of the methadone through his participation in a methadone maintenance treatment clinic and provided the district attorney with a letter from the clinic's project director to his attorney that affirmed his participation in the program and the clinic as the source of the methadone in his possession. 99 The district attorney issued the subpoena to the clinic to respond to the defendant's reliance on the letter. ${ }^{100}$

The clinic moved to quash the subpoena, and the trial court granted the motion with respect to the defendant's records, but permitted the district attorney to subpoena witnesses from the clinic regarding its operations. ${ }^{101}$ The trial court relied on People $v$. Newman and its interpretation of the protections afforded under the 1970 Act in quashing the subpoena and rejected the physician-patient privilege as protection for the records. ${ }^{102}$

On appeal, the Court ordered the ruling on the motion to quash modified to order production of Defendant's records from the clinic to allow the district attorney "to make such limited inspection and disclosure of those portions of the said books and records as it finds relevant to the guilt or innocence of said defendant on the charge mentioned and described in the indictment herein." 103 In reaching this conclusion, the court noted that "the sole issue involved in Newman was whether under the Federal statute the director could be compelled to divulge the identity of participants in the programs to the witness and the police."104 Unlike Newman, in this case, the clinic is:

not protecting the anonymity of the defendant against identification

95. Id

96. People v. Still, 369 N.Y.S.2d 759 (App. Div. 1975).

97. Id. at 760-61. In Still, the Certificate was issued under the authority granted to the Attorney General. Id. at 763 n.3.

98. Id. at 761 .

99. Id.

100. Id.

101. Id.

102. Id. at 761-62.

103. Id. at 762 (internal quotation omitted).

104. Id. at 763 . 
as a participant in the methadone treatment program, for he himself has disclosed his identity .... Thus, by electing to defend on the basis that the bottle of methadone was lawfully possessed by him in connection with his participation in [the methadone treatment] program, he has himself waived the benefit of the statutory right to anonymity. 105

Moreover, the Court concluded that:

To quash the subpoena in this case, as the Criminal Term has done, on the theory that the statute mandates such a result in order to protect the anonymity of the patient, when he himself has not only revealed his identity but strenuously insists, as a defense to his prosecution, that he was a patient, would be giving it (the statute) a tortured and illogical construction. ${ }^{106}$

Allowing only access to records that address the truth of the defendant's claim about his lawful possession of methadone gives the district attorney what fairness requires, without jeopardizing the clinic's programs. ${ }^{107}$

North Carolina v. Bradley. ${ }^{108}$ In North Carolina v. Bradley, Bradley was a criminal defendant charged with "indecent liberties with a minor" and statutory rape. ${ }^{109}$ Prior to trial, Bradley subpoenaed research records pertaining to his granddaughter from a study conducted by researchers from Duke University Health Systems. ${ }^{110}$ He sought the records to use for impeachment purposes. ${ }^{111}$ The granddaughter was a prosecution witness who was expected to testify, (and ultimately did), that Bradley had sexually abused her. ${ }^{112}$ Duke moved for a protective order on the grounds that the Certificate protected the study data, which the trial court granted. ${ }^{113}$ However, Duke

105. Id. at 765 .

106. Id.

107. Id. at $765-66$.

108. North Carolina v. Bradley, 634 S.E.2d 258 (N.C. Ct. App. 2006).

109. Id. at 260 .

110. Id.

111. Id.

112. Id. at $260-61$.

113. Id. at 260. The protective order was issued after an initial order to produce the documents, which would have permitted the study documents "to be read by the state's chief investigating officer, the witness, the District Attorney's office staff, the defendant and his wife, the Public Defender's office staff, the Assistant Public Defender, and any expert the defendant or state might consult." Compelled Disclosure of Data, supra note 23, at 1054. Additionally, the trial judge had no prior experience with Certificates and, like the appellate court, focused first on whether the defendant had met a burden to demonstrate a need for the documents. Id. 
was ordered to "maintain a sealed copy of the records ... until the final adjudication of all issues in this case, including any appeals or until further order of [the] court."114

After a jury convicted Bradley on all the charges against him, his appellate lawyer moved for access to the Duke files "to ensure a full and fair appellate review."115 The trial court ordered disclosure of the study documents to Bradley's appellate lawyer "for the purpose of determining whether any error should be assigned premised on their contents." 116 Access to the documents was restricted to the parties' lawyers. ${ }^{117}$ Duke appealed the order requiring disclosure.118

Bradley sought to set aside Duke's appeal, but the court permitted it to go forward, holding that Duke

is a party aggrieved and is asserting its legal rights, which have been directly affected by the trial court's order. The trial court's order effectively requires [Duke] to disclose information concerning the research subject's privacy which it is obliged, pursuant to the Certificate of Confidentiality and federal statutes, to protect. 119

Despite this recognition of the obligations the Certificate imposed on Duke, the appellate court did not rely on the Certificate in its decision. Rather, the court relied on the lack of evidence of materiality of the records to determine the case. According to the court, the matters potentially contained in the Duke records were "at best tangential" to the case and, thus, could not have been used by Bradley to impeach his granddaughter, even if there were evidence of inconsistent statements. ${ }^{120}$ Therefore, the court concluded that "[s]ince defendant has failed to satisfy the threshold requirement of materiality, ... he was not entitled to production or in camera review of the documents[,] and we need not consider [Duke's] argument that the confidentiality of the documents was statutorily privileged." 121 The appellate court found that the trial court erred in ordering the documents produced and vacated that order, ${ }^{122}$ but, at that point, the disclosure had already been made. ${ }^{123}$

114. Bradley, 634 S.E.2d at 260.

115. Id. at 261 .

116. Id.

117. Id.

118. Id.

119. Id. at 262 .

120. Id. at $262-63$.

121. Id. at 262 .

122. Id. at 263.

123. Compelled Disclosure of Data, supra note 23. 
Murphy $v$. Philip Morris Inc. ${ }^{124}$ The discovery dispute in Murphy v. Philip Morris Inc. arose in a personal injury suit against Philip Morris. ${ }^{125}$ The plaintiff, Robert Murphy, claimed that he contracted lung cancer through exposure to secondhand smoke, and Philip Morris sought the raw data from a study conducted by the University of Southern California (USC), the California Department of Health Services, and others, which was pivotal to the United States Environmental Protections Agency's conclusion that second-hand smoke causes lung cancer. ${ }^{126}$ Philip Morris moved to compel production of the raw data from USC, and the State of California joined USC in opposing the motion. ${ }^{127}$ According to the Court, USC presented "a compelling case... that the data itself (where the names and addresses of the participant and family members have been redacted) in at least in several instances can be used by a reasonably capable researcher to identify the subject that the data reflect." 128 The court also recognized that, because the study for which the data was sought was federally funded, USC had obligations to preserve the confidentiality of "the names and 'identifying characteristics' of the subjects," citing to obligations under the consent provisions of the Common Rule and to the Certificate authorizing statute. ${ }^{129}$ Nevertheless, the court ordered production of the data, in part because "the data itself without further inquiry does not automatically identify any participant" and Philip Morris asserted that "it ha[d] no intention of using the raw data to identify any of the study participants." 130 That production was subject to a protective order that, among other things, (1) imposed restrictions on attempts to re-identify the subjects; (2) limited use of the documents to the particular case; (3) limited the disclosure of the documents to specified individuals who must first sign a non-disclosure agreement; and (4) required return of the documents after the

124. Order Granting Defendant Philip Morris' Motion to Compel Production of Documents in Response to Subpoena Duces Tecum; Protective Order, Murphy v. Philip Morris Inc., No. CV 99-7155-RAP (JWJx) (C.D. Cal. Mar. 17, 2000).

125. Id. at 1 .

126. Id. at $1-2$.

127. Id. at 2 .

128. Id. at 4 .

129. Id. at 5 (citing 45 C.F.R. $\S 46.116(\mathrm{a})(1)-(5)$ (part of the Common Rule) and 42 U.S.C. $§ 241(d)$ (the Certificate authorizing statute)).

130. Id. at $4-5$. 
case was concluded. 131

What is most interesting about the Murphy case is that, despite the citation to the Certificate authorizing statute, it does not appear that the study had a Certificate and, thus, that the statute had any bearing on the case before the court. The published order never indicates that the study had obtained a Certificate. Reports from the study do not indicate that the study had a Certificate. ${ }^{132}$ So why does the court's order reference 42 U.S.C. $\S 241(\mathrm{~d})$ ? It appears that the court adopted the arguments presented by USC's counsel in its "Opposition of Third Party University of Southern California to Defendant Philip Morris' Motion to Compel Production of Documents in Response to Subpoena Duces Tecum to Records Custodian and/or to Dr. Anna Wu." 133 In their opposition, USC's attorneys raise several arguments against the disclosure of the data first under California law and then under federal law. In section IX of their opposition brief, "Federal Statutes and Regulations Protect the Study Participants' Confidentiality and Weigh in Favor of Nondisclosure," appearing on page 20 of the motion, USC's attorney argued that:

45 C.F.R. Section 46.116(a)(1)-(5) [part of the consent sections of the Common Rule], coupled with 42 U.S.C. 241(d), set the minimum federal privacy requirements that must be observed. 42 U.S.C. 241(d) requires that the privacy of any individual who acts as a research subject be protected "by withholding from all persons not connected with the conduct of such research the names or other identifying characteristics of such individuals. Persons so authorized to protect the privacy of such individuals may not be compelled at any Federal, State or local civil, criminal, administrative, legislative or other proceedings to identify such individuals. (emphasis added) ${ }^{134}$

131. Id. at 6-7.

132. We searched PubMed for publications from the study. We also searched Google for study documents. The failure to report the existence of a Certificate in publications from the study is not definitive evidence that the study had no Certificate. Coffey and Ross found that researchers did not always report the existence of a Certificate in their publications. Coffey \& Ross, supra note 1 . However, as described in more detail later, the documents filed on the motion further support the conclusion that the study did not have a Certificate. See infra note 135.

133. Opposition of Third Party University of Southern California to Defendant Philip Morris' Motion to Compel Production of Documents in Response to Subpoena Duces Tecum to Records Custodian and/or to Dr. Anna Wu, Murphy v. Philip Morris Inc., No. 99-07155 CM (JWJx) (C.D. Cal. Aug. 26, 1999) (on file with authors). To understand the reference, we obtained court documents relating to the motion to compel from the National Archive in Southern California. These documents are available from the authors.

134. Id. at 20 (bold emphasis added) (italic emphasis in original). 
This argument appears to be a misunderstanding of 42 U.S.C. $\S 241(d)$, which grants the Secretary authority to grant researchers the ability to resist subpoenas for research participants' identifying information, but does not extend that authority to all research projects. ${ }^{135}$ In its reply, Philip Morris' attorneys did not address the argument, except to note that it did not seek identifying information. Thus, it appears that the court may have perpetuated this misunderstanding.

\section{UNREPORTED CASES INVOLVING CERTIFICATES}

Because of the paucity of reported cases involving Certificates, and the limited legal analysis about Certificates within those cases, we sought to identify cases at any level that might involve Certificates and add to our understanding of how courts address them. ${ }^{136}$ Through our database searches, we were able to identify some additional cases, although the amount of information available on each was variable.

In re: Louisville Branch-National Association for the Ad-

135. That this is a misunderstanding is further reinforced by review of the Opposition to the motion and supporting documents. The Opposition quotes portions of the consent form referring to general promises to maintain the confidentiality of data, but no reference to the language required by $\mathrm{NIH}$ when a Certificate is issued. The quoted sections are consistent with the language in the California Department of Health consent forms for the study that are attached as Exhibits to the Memorandum in Opposition to Defendant Philip Morris' Motion to Compel Production of Documents by Intervenor and Interested Third Party, State of California, Department of Health Services. Memorandum in Opposition to Defendant Philip Morris' Motion to Compel Production of Documents by Intervenor and Interested Third Party, State of California, Department of Health Services; Exhibits, Murphy v. Philip Morris, Inc., No. CV-99-07155 RAP (JWJx) (C.D. Cal. Aug. 25, 1999) (on file with the authors). It is similarly consistent with Dr. Wu's description of the consent process in the study, related in the Transcript of Hearing before the Honorable Jeffrey W. Johnson. Further Hearing Re Defendant Philip Morris' Motion to Compel Production of Documents in Response to Subpoena Duces Tecum to Records Custodian of/or to Dr. Anna Wu at 62-68, Murphy v. Phillip Morris, Inc., No. 99-7155-RAP (JWJX) (C.D. Cal. Dec. 16, 1999)(on file with authors).

136. To identify cases that have not reached the appellate level, we searched the "All Federal and State Briefs and Motions, Combined" database on Lexis and "Trial Motions" database on Westlaw for all cases that referred to the Certificate statute, regulations, or key words "Certificate" and "confidentiality" in close proximity. We note that neither of these databases is comprehensive. We also conducted searches on Google for additional cases, using similar approaches. If we identified a case through these means, but did not find relevant documents (e.g., moving papers or order), we sought to obtain those documents through appropriate sources, including the PACER database for federal cases, on-line state databases, and contacting the state court. 
vancement of Colored People/Administrative Office of the Courts and the University of Louisville. ${ }^{137}$ This is a Kentucky Attorney General's Opinion regarding a dispute between the Louisville Branch of the National Association for the Advancement of Colored People (NAACP) and the Administrative Office of the Courts (AOC) and the University of Louisville (Louisville). The AOC commissioned Louisville to conduct a study of the court to evaluate racial fairness in sentencing. 138 AOC provided data extracted from court records to Louisville for the research. 139 The data included, among other things, information about judges, race of defendants, and length of sentences imposed. ${ }^{140}$ Louisville agreed to strict confidentiality, including the coding of data to protect the identity of the judges (among other things). ${ }^{141}$ The results of the study were reported in $R a$ cial Fairness in Sentencing: A Case Study of Selected Crimes in Jefferson County. ${ }^{142}$

The NAACP filed an open records request to the AOC and Louisville for the "supporting data, documents and other materials" for the report "to monitor the performance of [the] elected judiciary through records access." 143 The request specifically asked for the "names of all circuit and district court judges studied for the report, along with a breakdown of each respective judge's sentences studied for the report by the crime committed and the race of the defendant." 144 Both the AOC and Louisville denied the request on different grounds. ${ }^{145}$ Because Louisville had a Certificate, we focus on its arguments. Louisville asserted its Certificate independently and as incorporated through state public records law, KRS 61.878(1)(k), which authorizes the state to withhold information when its disclosure is prohibited under federal laws or regulations. ${ }^{146}$ The NAACP argued that Louisville's Certificate did not shield the data from disclosure because it was derived from publicly accessible court

137. Louisville Branch-Nat'l Ass'n for the Advancement of Colored People, 06-ORD-094 Op. Ky. Att'y Gen. (2006) [hereinafter Op. Ky. Att'y Gen.] (open records decision).

138. Id. at 2 .

139. Id.

140. Id. at 3 .

141. Id. at $3 \&$ n.2.

142. Id. at 1 .

143. Id. at 1-2.

144. Id. at 1 .

145. Id. at 1-2.

146. Id. at 4,9 . 
records. ${ }^{147}$ It also raised some technical challenges, questioning whether a behavioral study qualified for a Certificate, as well raising questions about its effective date. ${ }^{148}$ Louisville responded to each of the technical challenges the NAACP raised. In its opinion, the Attorney General found that the Certificate was controlling. ${ }^{149}$ After consulting with NIH legal counsel about the Certificate, the Attorney General was persuaded that the Certificate was legally in force for the study. ${ }^{150}$ Because it was valid, the Attorney General (AG) concluded that "[i]t therefore provides absolute protection against compelled disclosure of identifying information about the subjects of the study." 151 The AG goes on to indicate that "Louisville amply demonstrates the disputed data consists of "identifying information," relying on the FAQ of the NIH website for the definition of "identifying" as "any other item or combination of data about a research participant which could reasonably lead, directly or indirectly by reference to other information, to identification of that research subject." 152 Louisville had provided information demonstrating how someone could piece information from the data with publicly available documents to identify the judges. ${ }^{153}$ Based on this information, the AG concluded: "To require involuntary disclosure of the disputed data would be tantamount to breaching the protection afforded by the certificate through release of a combination of data about research subjects that could reasonably lead, directly or indirectly by reference to other information, to the identification of those subjects."154

In re Phenylpropanolamine (PPA) Products Liability Litigation. ${ }^{155}$ This case consolidates numerous products liability

\footnotetext{
147. Certainly, some of the information was publicly available. However, based on prior case law, the Attorney General found that the compilation of data derived from the AOC's records were not public records subject to the state open records. Id. at 6-9. The conclusion that the records were not public records further supports the Attorney General's finding that the Certificate protected the data that AOC shared with Louisville.

148. Id. at 3-4.

149. Id. at 8 .

150. Id. at 10 n. 11 .

151. Id. at 11 .

152. Id.

153. Id.

154. Id. at 12 .

155. Order Re: Motion to Quash Subpoenas Re Yale Study's Hospital Records, In re Phenylpropanolamine (PPA) Products Liability Litigation, No. 1407
} 
claims against drug manufacturers alleging that PPA contained in their products caused hemorrhagic stroke into a single, multi-district litigation (MDL). The MDL defendants subpoenaed 32 hospitals seeking records of 27 research participants from the Hemorrhagic Stroke Project. 156 Yale University had already produced data and underlying materials related to the study, including redacted versions of medical records. ${ }^{157}$ The MDL defendants were seeking additional medical records about the participants from the hospitals that provided them to the Yale researchers. ${ }^{158}$ According to the Court, the defendants requested redactions generally mirroring those conducted on the documents received from Yale (i.e., name; social security number; street address; last four digits of telephone number; family member names; birthday; doctors' names; etc.). ${ }^{159}$

Yale moved to quash the subpoenas on the grounds that the Certificate protected the data. 160 Although defendants indicated a willingness to accept redacted data, Yale argued it "is not confident the general redaction indication in the subpoenas suffices or that the redaction would be completed thoroughly and properly." 161 Yale pointed out that the subpoenas referred only to certain information being redacted and did not require a uniform redaction protocol (and asked the Court to impose a uniform redaction protocol if the subpoenas are enforced). ${ }^{162}$ Yale further noted the participants' expectations of privacy and the chilling effect on future research. ${ }^{163}$ That is, that providing full access to medical records might dissuade others in the future from participating in studies. ${ }^{164}$

In response, the MDL defendants made several arguments; we focus only those relevant to the Certificate. First, they disputed the concerns regarding patient confidentiality because they are requesting only redacted information, which they argued is consistent with a previous agreement with Yale, which

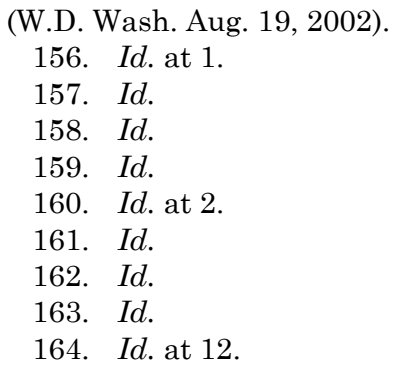


had already produced information. ${ }^{165}$ Defendants further argued that participants understood that others would have access to their records, and that the promise of protection was only to their identities, which is what the Certificate requires. ${ }^{166}$ Moreover, defendants contended that their subpoenas were narrowly tailored to request the records of the 27 cases who participated in the study and to which the stroke project investigators had access. ${ }^{167}$ Yale's earlier production undermined its claim of a chilling effect. ${ }^{168}$

In its order on the motion to quash, the Court focused on the defendants' rights under Federal Rule of Civil Procedure 26 and the broad discovery permitted under it, rather than on the terms of the Certificate. ${ }^{169}$ It concluded that the records that Yale had in the study or the records that supported the summary information sent to it are "unquestionably relevant." 170 The Court also concluded that "the confidentiality agreements already associated with those relevant documents, taken together with defendants' requests for redaction, mitigates any concern with respect to issues of confidentiality." 171 The Court agreed there should be a uniform redaction protocol and that the subpoenas should be narrowed to specify only medical records relevant to the stroke project, rather than other patients. ${ }^{172}$ In addressing the chilling effect argument, the court noted that "[t]he HSP [Hemorrhagic Stroke Project] has been concluded for some time, many thousands of HSP-related documents have been produced to date, and the patients involved in the HSP agreed to the disclosure of their relevant medical records, so long as any identifying information was redacted." 173

In re PremPro Products Liability Litigation. ${ }^{174}$ This case is

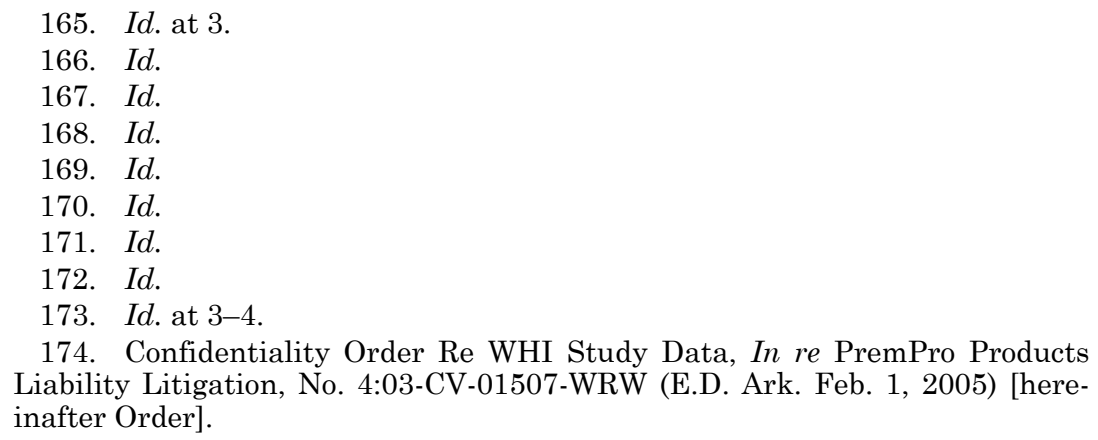

174. Confidentiality Order Re WHI Study Data, In re PremPro Products Liability Litigation, No. 4:03-CV-01507-WRW (E.D. Ark. Feb. 1, 2005) [hereinafter Order]. 
another set of products liability cases alleging that the hormone replacement therapy drug, PremPro, caused cancer. The relevant action for our purposes involved a request for a dataset from the Women's Health Initiative (WHI) study, which includes 161,000 postmenopausal women at 49 clinical sites throughout the United States. ${ }^{175}$ Fred Hutchinson Cancer Research Center (FHCRC) is the Clinical Coordinating Center and has the data from all the collaborating sites. ${ }^{176}$ FHCRC, at the National Institutes of Health's direction, produced data in 2002 in the litigation after redacting identifying information according to a National Heart, Lung and Blood Institute protocol. ${ }^{177}$ Wyeth sought additional information and ultimately moved to compel production. ${ }^{178}$ Wyeth agreed that any production is subject to a confidentiality order "that bars Wyeth and any other recipient of the data in the litigation from attempting to identify the WHI study participants."179

In its opposition to Wyeth's motion, FHCRC indicated it asked Wyeth to enter into a protective order, "allowing data responsive to Wyeth's subpoenas to be used in the litigation, while protecting the privacy of the study participants; ensuring the contractual rights of FHCRC and its investigators in publication of study results; and complying with its contractual responsibilities to the National Institutes of Health ("NIH")."180 It also made an argument about burden, suggesting that it remove additional information (by hand), including Clinical Center Identification to protect participant identities because such

175. Memorandum in Opposition to Wyeth's Motion to Compel and Motion for Protective Order Re Production of Records by Fred Hutchinson Cancer Research Center, a Non-Party Witness at 2, In re PremPro Products Liability Litigation, No. 4:03-CV-01507-WRW (E.D. Ark. Nov. 30, 2004) at 2 [hereinafter FHCRC memorandum].

176. Id.

177. Id. at 4 .

178. Motion to Compel Production of Documents from the National Institutes of Health and the Fred Hutchinson Cancer Research Center, In re PremPro Products Liability Litigation, No. 4:03-CV-01507-WRW (E.D. Ark. Nov. 12, 2004).

179. Id. at 1

180. FHCRC memorandum, supra note 175 , at 1 . It is worth noting that FHCRC's "Issue Presented" focused on whether there should be a protective order before production, rather than on the protections afforded by the Certificate, and that its legal argument about the Certificate's protections appeared on page fifteen of a twenty-four-page memorandum and was only one paragraph long. Id. at 15 . 
information could be used to re-identify participants. ${ }^{181}$ Wyeth disputed this claim of possible re-identification and further noted that the parties had been negotiating a protective order that would prohibit Wyeth from seeking to re-identify participants. ${ }^{182}$ FHCRC's other arguments included the right of WHI investigators to reap the benefit of publishing their work and the potential chilling effect on future research if information is disclosed. ${ }^{183}$

In response to the motion to compel, the court ordered production of data, but with a protective order that provided that the data "will not contain such participant identifiers as are required to be deleted by the National Heart, Lung and Blood Institute policy for preparation, release and public distribution of public use data; the certificate of confidentiality; and state and federal law." 184 Anyone receiving the data had to sign the Conditions of Disclosure form. ${ }^{185}$ Use was limited to the litigation, people receiving the data could not publish the data until published by the WHI investigators, and were required to return or destroy the data at the end of the litigation. 186 The order did not contain an agreement prohibiting attempts to re-identify participants.

Dummit v. CSX Transportation, Inc. ${ }^{187}$ In this case, current and former employees of CSX Transportation Inc. (CSX) alleged workplace chemical exposures caused their injuries. CSX subpoenaed magnetic resonance imaging (MRI) results from Mark Haut, Ph.D. at West Virginia University for use in its defense. ${ }^{188}$ These results were from a study about occupational exposures conducted by Dr. Haut and funded by the Na-

181. Id. at 6 .

182. Motion to Compel Production of Documents from the National Institutes of Health and the Fred Hutchinson Cancer Research Center at 2, In re PremPro Products Liability Litigation, No. 4:03-CV-01507-WRW (E.D. Ark. Dec. 8, 2004).

183. FHCRC memorandum, supra note 175, at 7-8.

184. Order, supra note 174 , at 1.

185. Id. at 1 .

186. Id. at $1-3$.

187. Dummit v. CSX Transport, Inc., No. 01-C-145 (Cir. Ct. W. Va. Nov. 21, 2006) (on file with authors).

188. Response of Defendant CSX Transportation, Inc. to Combined Motion to Quash Subpoena and Motion for Protective Order at 2-3, Dummit v. CSX Transportation, Inc., 01-C-145 (Cir. Ct. W. Va. Dec. 6, 2006) (on file with authors) [hereinafter Response]. 
tional Institute for Occupational Safety and Health and Centers for Disease Control and Prevention. ${ }^{189}$ Dr. Haut's study had obtained a Certificate and sought to quash the subpoena based on its protections, as well as state law grounds. 190 CSX countered that the Certificate did not apply because CSX did not seek any subject-identifying information. ${ }^{191}$ As it described, it sought "access only to the underlying data after it is stripped of identifiers." 192 Although a hearing on the motion to quash was scheduled before a state Circuit Court Judge on December 7, 2006, the court did not address the Certificate's protection because the parties arrived at the hearing having resolved the dispute. ${ }^{193}$ The parties agreed that Dr. Haut would produce most of the requested data to an independent researcher after he "anonymized" the data. ${ }^{194}$ As described by the parties, the thirty-one data sets would contain no identifiers, but would only reference whether they were a case or control.195 In addition, they agreed to limit disclosure of the data. 196 They further expressed their intention to document the agreement following the hearing. ${ }^{197}$

Juvenile court case. 198 In this case, the Connecticut Commissioner of the Department of Children and Families filed an application for temporary custody of four children, which was granted. 199 The children had participated in two research projects conducted at Yale and protected by a Certificate. ${ }^{200}$ One study evaluated an intervention for children in out-of-home care because of abuse and neglect and the other evaluated

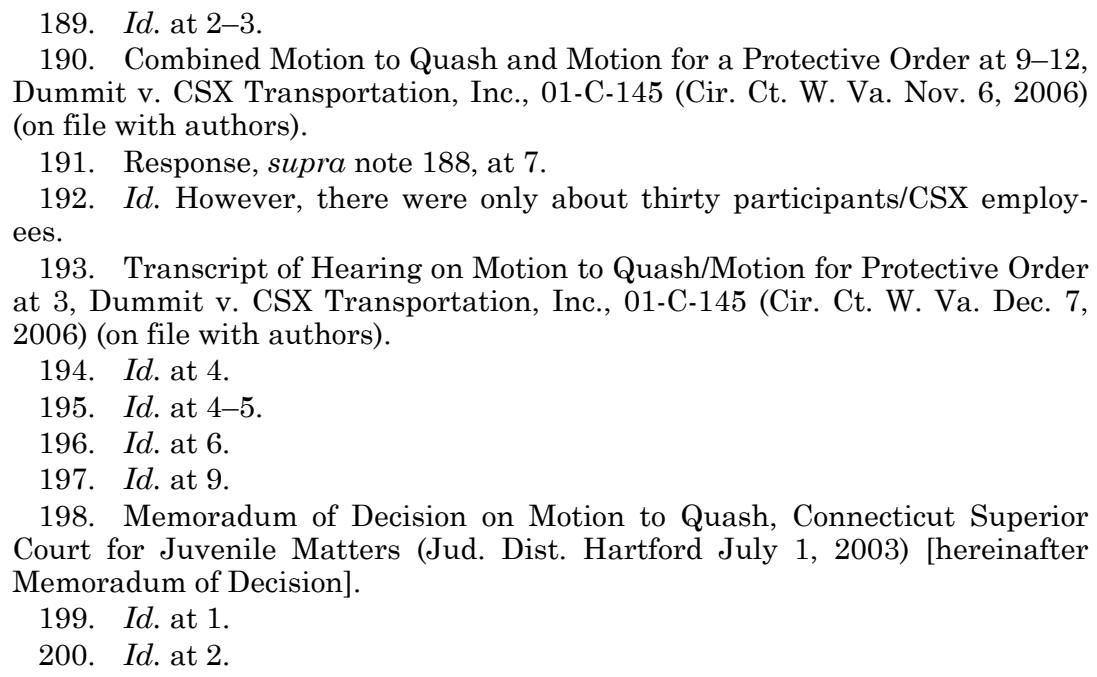


stress on brain development. ${ }^{201}$ The Department of Children and Families (the Department) subpoenaed those records, contending that the records were necessary to providing appropriate medical treatment to the children. ${ }^{202}$ The Department learned about the children's study participation from Yale researchers when they voluntarily notified the Department of concerns about the children's welfare. ${ }^{203}$ The opinion in this case resulted from Yale's motion to quash the subpoena.

Yale made two arguments in favor of its motion to quash: first, the records were protected by a Certificate and, thus, are "privileged, confidential and protected from disclosure under federal law," and, second, that disclosure would violate public policy. ${ }^{204}$ In response, the Department argued that the statutes authorizing Certificates do not prohibit disclosure of the records, that Yale waived any protection, and that the Yale researchers were mandated reporters and so must "fully disclose" any information in its possession related to child abuse. ${ }^{205}$

The Court ultimately agreed with the Department's interpretation of the Certificate statute that it only prohibited Yale from disclosing the names and other information from which the identity of the subjects can be ascertained, not the underlying records. ${ }^{206}$ The Court determined that three cases that discuss 42 U.S.C. $§ 241(\mathrm{~d})$, People v. Newman, People v. Still, and Murphy v. Phillip Morris Inc., support the Department's argument because each court focused on the prohibition of disclosure of identifying information, not the records themselves. ${ }^{207}$ The Court noted that, to the extent it is unclear whether 42 U.S.C. $§ 241(\mathrm{~d})$ "is intended to protect only the identity of research subjects or the substance of the research," Connecticut courts would defer to a federal agency's interpretation of the statute. ${ }^{208}$ Based on its review of the implementing regulations, the Court decided these, too, support the Department's interpretation that they apply only to identifying information, not

201. Id. at $1 \mathrm{n} .1$.

202. Id. at 2 .

203. Id. at 9,11 .

204. Id. at 2 .

205. Id.

206. Id. at 3 .

207. Id. at 6 .

208. Id. at 7 . 
the records in question. ${ }^{209}$

Critically, in this case, both sides agreed that "Yale informed the department that the children were participating in its research project," 210 and the court agreed with the Department's contention that this disclosure constituted a waiver of the Certificates' protections. ${ }^{211}$ The Court concluded that the Department's position is supported by People v. Still, which, according to the court, stands for the proposition that "the subject of a research study may waive his or her right to remain anonymous"212 and the regulations (and the Certificate language), which allow the researcher to voluntarily disclose identifying characteristics of research subjects in certain circumstances, e.g., child abuse. ${ }^{213}$ From this, the Court concluded "[t]he regulations and the certificates thus imply that the subject as well as the entity and individual conducting a research program may waive the right to refuse to disclose identifying information."214 Because Yale voluntarily disclosed to the Department that the children were participating in the research projects, the Court concluded that Yale has waived its right to refuse to disclose identifying information to the Department. 215

Yale also asserted that disclosing the records would violate public policy because it would have a chilling effect on public participation in research. ${ }^{216}$ This policy is recognized in Murphy v. Philip Morris Inc., as well as People v. Newman. However, the court noted that, "[i]n circumstances such as this, however, where allegations of child abuse are involved, another public policy [protecting children from abuse and neglect] is also implicated." 217 This Court agreed that the policy of protecting the identity and records of research subjects must "give way to the extent necessary to accommodate the dominant public policy of protecting children," which it argued was consistent with the balancing courts have made in other contexts involving confi-

\footnotetext{
209. Id. at 8-9.

210. Id. at 9 .

211. Ironically, the researchers informed the Department about the children's participation in the study because they sought to protect them; they had concerns about "the ability of the children's mother to care for them." Id. at 9.

212. Id. at 10 .

213. Id. at $9-11$.

214. Id. at 10 .

215. Id. at 11 .

216. Id. at 14 .

217. Id. at 14-15.
} 
dentiality versus child protection. ${ }^{218}$

In ordering Yale to provide the Department with the requested documents, the Court provided some confidentiality protections; it restricted the use of the records to providing treatment for the children, required Yale to redact the names and other identifying information from other research participants and their parents, ${ }^{219}$ and prohibited the Department from seeking to re-identify any research subject or to disclose information about them. ${ }^{220}$ It is unclear from the Memorandum why the Department needed the research records, given that it had already obtained temporary custody of the children and, thus, was in a position to provide medical treatment.

Experiences reported by institutional counsel. As reported in more detail elsewhere, ${ }^{221}$ institutional legal counsel have described in interviews experiences similar to those reflected in the cases described above.222 Most counsel (20/24) had experience with legal demands for research data, and almost twothirds reported having experience with legal demands for research data protected by a Certificate. ${ }^{223}$ Most cases that counsel described were civil, not criminal, ones. ${ }^{224}$ Overall, counsel reported that they generally were able to resolve cases without

218. Id. at 16. Of course, the researchers' recognized the interest in protecting the children in contacting the Department about their concerns. Although we do not have access to the consent form in this case, researchers who obtain a Certificate are required to include any circumstances in which they will reveal identifiable information in the consent form. 42 C.F.R. § 2a.4(j) (2011) (discussed in Part II.B). See also the sample consent language in Detailed Application Instructions for Certificate of Confidentiality: Extramural Research Projects, U.S. DEP'T HEALTH \& HUM. SERVICES, http://grants.nih.gov/grants/policy/coc/appl_extramural.htm (last updated Dec. $23,2009)$. In doing so, they typically indicate that they will reveal information about the abuse, but not everything that they have learned about the participant through the study. See, e.g., Consent Process-Certificate of Confidentiality, S.F. COMM. ON HUM. RES., http://www.research.ucsf.edu/ chr/Recruit/chrConsentCertConf.asp (last updated Aug. 1, 2011).

219. It is not clear from the Court's Memorandum of Decision whether the Department sought access to records beyond the four children over whom the Department had temporary custody. Unfortunately, we do not have access to the parties' papers to help answer this question.

220. Memorandum of Decision, supra note 198, at 17.

221. Wolf et al., supra note 17.

222. Id. The results are based on semi-structured interviews with twentyfour institutional legal counsel.

223. Id. at 3 .

224. Id. 
going to court and without disclosure of identifiable data.225 Counsel described multiple strategies they had successfully used in protecting research data. In some cases, simply informing opposing counsel about the Certificate was sufficient. ${ }^{226}$ In others, counsel were able to persuade the requesting attorney to obtain the information from other sources. ${ }^{227}$ In some cases, counsel negotiated disclosure of nonidentifiable data.228 Even when required to go to court, counsel indicated that they were often successful in protecting the data, although they typically relied on other legal protections, rather than the Certificate. ${ }^{229}$

\section{E. IMPLICATIONS OF THE CASES}

Several lessons can be taken away from our review of the cases we uncovered-reported and unreported-involving Certificates. First, the cases and the experiences of counsel suggest that Certificates generally function as intended. Counsel often are able to avoid both production of data and court fights over production, by informing the requesting counsel about the Certificate and its protections. When data are produced, typically only limited data are produced to avoid identification ${ }^{230}$; such production is consistent with the Certificate's protection, although perhaps not with people's ordinary understanding of the protections. ${ }^{231}$

Second, despite this overall reassuring picture of data pro-

225. Id.

226. Id. at 6 .

227. Id.

228. Id.

229. Id.

230. See, e.g., supra notes $155,174,187$. This is what happened in the PPA, Prempro, and CSX cases, as well as in cases described by counsel in our interviews. As described in these cases, a protective order typically was also issued with additional confidentiality obligations, such as limiting access to the data and promising not to reidentify subjects using other available data. However, such protections may not always be sufficient. One counsel in our interviews described a circumstance in which research data (not protected by a Certificate) was ordered produced in a deidentified form, but where the counsel felt deidentification was not truly feasible because of the small number of subjects (under twenty) and the specificity of the data collected (unpublished data). Wolf et al., supra note 17.

231. In our interviews with legal counsel, one respondent described learning that the Certificate protects only identifiable data, "contrary to some people's assumptions." Wolf et al., supra note 17, at 4. Some IRB Chairs reflected the assumption that the Certificate protected all data, with one describing a researcher with a Certificate as being "free of the obligation to deliver data in a lawsuit." Institutional Review Board, supra note 22, at 5. 
tection, the cases reveal some important areas of concern. Significantly, the cases reveal some uncertainty and confusion about Certificates and their protections. Specifically, despite the strong statutory language, it appears that when research data are sought, counsel and judges do not start by considering whether the Certificate protects the data, but rather simply view the Certificate as one aspect among many to be considered; although the statutory language sounds definitive, counsel and judges do not approach Certificates that way. For example, in the PremPro case, Fred Hutchinson's lawyers raised the Certificate's protection as their third legal argument in the memorandum in opposition to Wyeth's motion to compel. ${ }^{232}$ Similarly, the Bradley court did not even address the Certificate's protections, having decided the issue on ordinary discovery concepts of materiality. ${ }^{233}$ This approach, perhaps, is not so surprising given that lawyers encounter few Certificate cases in their careers and may not be too familiar with them. ${ }^{234}$ Given how few cases go to court, judges are even less likely to encounter Certificates and, therefore, may be likely to approach demands for research data the same way they approach other discovery disputes about sensitive, confidential data. However, this apparent hesitancy to raise the Certificate as a primary argument to protect data may also reflect uncertainty about whether courts will uphold a Certificate's protection. In interviews, counsel certainly expressed concerns about the strength of the protections and reluctance to assert the Certificate where there were other protections on which to rely. As one counsel explained, "I guess the prevailing thought or position is that we don't want to challenge [Certificates] in court and set precedent for the court saying they're not effective."235

Finally, judicial treatment of two critical issues related to the Certificate's protections-waiver and identifiability-in some cases seem to validate counsels' concerns about how Certificates will fare in the courts. The two waiver issues that arise

232. FHCRC Memonrandum, supra note 175, at 15. This argument does not appear until page fifteen of a twenty-four-page memorandum in opposition to the motion to compel. $I d$.

233. State v. Bradley, 634 S.E.2d 258, 262 (N.C. Ct. App. 2006).

234. Wolf et al., supra note 17 , at 3 . This lack of familiarity may explain counsel's reliance on the Certificate as a general confidentiality obligation in the Philip Morris case and the court's perpetuation of this error.

235. Id. 
are 1) whether waiver has occurred, and 2) the scope of the waiver. The first case to address waiver was People v. Still. In Still, the court had to determine whether the methadone clinic could assert the Certificate's protections against the district attorney's subpoena, when the patient, Still, had already indicated he was a patient at the clinic and, with Still's permission, the clinic had provided information confirming his participation to support his defense. ${ }^{236}$ The court appropriately concluded that Still's disclosure constituted a waiver of the Certificate's protections, although only with respect to records that would "aid in determining the veracity of the defendant's claim of lawful possession of the methadone found on him." 237 In Still, the waiver was voluntary, purposeful, and limited in scope.

The opposite is true in the juvenile court case. While it is true that the researchers' disclosure of the pediatric participants' identities was voluntary, the waiver of the Certificate's protections could hardly be said to be voluntary and purposeful, nor was the waiver limited in scope. The juvenile court judge interpreted the researchers' disclosure of participant identities to report child neglect as a waiver of the Certificate's protections. ${ }^{238}$ This interpretation appears inconsistent with both the researchers' intentions, as evidenced by their motion to quash the subpoena for the records, ${ }^{239}$ and with the intent of the statute and implementing regulations. Specifically, the statute is permissive-researchers may withhold identifying characteristics-and the regulations expand on that concept by making it explicit that the Certificate does not apply to voluntary disclosures. 240 The NIH Certificate kiosk expands on the issue of voluntary disclosures in its "frequently asked questions" section, explaining,

Personally identifiable information protected by a Certificate may be disclosed under the following circumstances: ... Voluntary disclosure by the researcher of information on such things as child abuse, reportable communicable diseases ... possible threat to self or other, or other voluntary disclosures provided that such disclosures are spelled out in the informed consent form; Voluntary compliance by the researcher with reporting requirements of state laws, such as knowledge of communicable disease, provided such intention to report

236. People v. Still, 369 N.Y.S.2d 759, 761 (App. Div. 1975).

237. Id. at 765 .

238. Memorandum of Decision, supra note 198, at 11.

239. Id. at 1 .

240. See supra Parts II.A, II.B (discussing the statutory and regulatory provisions). 
is specified in the informed consent form. ${ }^{241}$

With respect to communicable disease, NIH policy requires an agreement to comply with state disease reporting requirements in order to receive a Certificate. ${ }^{242}$ If disclosure of limited but identifiable information for reporting purposes waived the Certificate's protections, this NIH policy would be nonsensical, because the agreement to report would render the Certificate's protections meaningless. The court's waiver interpretation creates a strong disincentive to reporting conditions that the NIH explicitly requires for disease reporting and encourages for abuse reporting.

The juvenile court case also highlights some problems concerning the concept of identifiability. In that case, the judge appears to consider only the identity to be protected. In the judge's view, once the researchers revealed to the department the names of four children who were participating in the study, there was no reason to keep any data relating to them confidential. ${ }^{243}$ This interpretation appears to be too narrow. Certainly when Certificates' protections only applied to illegal drug use, identity was the critical issue. Identifying someone as a participant revealed sensitive information about them-that is, that they had engaged in illegal activity. But even then, identity in and of itself was not the only issue. Rather, it was-and is-the individual's identity in connection with some other information (originally, use of illegal drugs) that creates the risk to participants, and that the statute addresses. This point is reinforced in the illegal drug use context by considering that there are different legal penalties for possessing different types of drugs, as well as different levels of opprobrium and stigma attached to such use; for example, marijuana use is judged less harshly than heroin use. Thus, the harm to a person identified as participating in a study of illegal drug use could be harmed further by also revealing specific information about her drug use. That the connection between the data and the identity is the important consideration is also evident from the way that NIH describes research topics that are appropriate for a Certificate's protection, under the current, broader statute. For ex-

241. FAQs on Certificates, supra note 1.

242. Reporting of Communicable Diseases Policy, U.S. DEP'T HEALTH \& HUM. SERVICES (Aug. 9, 1991), http://grants.nih.gov/grants/policy/coc/ cd_policy.htm.

243. Memorandum of Decision, supra note 198, at 10. 
ample, NIH lists "[s]tudies that gather information that if released could be damaging to a participant's financial standing, employability or reputation within the community; [r] esearch involving information that might lead to social stigmatization or discrimination if it were disclosed" as studies eligible for a Certificate. ${ }^{244}$

Viewed against this background, the juvenile court's ruling is inconsistent with the purpose of the Certificate. Moreover, if other courts were to follow this approach, such decisions could ultimately stifle the type of research that Certificates are intended to encourage. While it seems likely that the court's interest in protecting the health and well-being of the children factored into its ultimate decision to require disclosure of the data, it is not clear that disclosure of the data was necessary to do so. Indeed, the researchers already had disclosed to the Department of Children and Families their concerns about the children's welfare, and, as a result, the Department had custody of the children. ${ }^{245}$ It is difficult to understand how, under such circumstances, the data could enhance the Department's ability to protect the children; the Department could access medical records, as well as speak with the children, their doctors, and others who had information about them to get information that might help in their care. Moreover, had the researchers understood that identified data would be subject to compelled disclosure if they reported their concerns, they may have hesitated to disclose, which would have decreased protection for the children.

The Attorney General's opinion in In re NAACP $v$. University of Louisville stands in stark contrast to the juvenile court case. Rather than focusing solely on identity, the Attorney General recognized that it was being connected to the data collected that could be harmful to participants because it could result in them being labeled racist within their community. ${ }^{246}$ The Attorney General also understood that the results produced by the study were valuable, and could not be obtained unless participants felt that they would not be connected to the information collected in the study. 247 Accordingly, the Attorney General looked carefully at whether, in combination with other

244. FAQs on Certificates, supra note 1.

245. Memorandum of Decision, supra note 198, at 1, 9.

246. Op. Ky. Att'y Gen., supra note 137, at 10.

247. Id. 
information, the research data could become identifiable in ways that could be harmful to participants. 248 This more sophisticated view recognized limits in our ability to share data in a deidentified fashion and maintain that deidentification in today's world. The role of technology in the concept of identifiability is discussed in more detail in Part V.

\section{OTHER STATUTORY CONFIDENTIALITY PROTECTIONS}

The HHS Certificate is not the only statutory protection for research data. There are several other federal protections, although they differ in important ways from the Certificate statute. In addition, states have adopted statutes to protect research data in some circumstances. Like the HHS Certificate, there are few reported cases involving these statutes.

\section{A. Federal Statutes}

\section{Protection of Substance Abuse Records}

Statutory protection. As described above, the court in People $v$. Newman, determined that the 1972 Act did not repeal the 1970 Act with respect to the confidentiality of records. ${ }^{249}$ In doing so, the court noted the differences between the protections afforded by the two acts, including that the 1972 Act did not need to offer the same "guarantee of anonymity" because it "covered a wide range of programs and activities [not just research] ... in which absolute confidentiality was not regarded as a prerequisite to successful operation of the programs." 250 What the 1972 Act did provide in terms of confidentiality was as follows:

Records of the identity, diagnosis, prognosis, or treatment of any patient which are maintained in connection with the performance of any program or activity relating to alcoholism or alcohol abuse education, training, treatment, rehabilitation, or research, which is conducted, regulated, or directly or indirectly assisted by any department or agency of the United States shall ... be confidential and be disclosed only for the purposes and under the circumstances expressly authorized under subsection (b) of this section. ${ }^{251}$

248. Id. at 12 .

249. People v. Newman, 298 N.E.2d 651, 657 (N.Y. 1973).

250. Id. at 656 .

251. Drug Abuse Office and Treatment Act of 1972, Pub. L. No. 92-255, 
Subsection (b) covered disclosure upon, on the basis of prior written consent of the patient and without consent for bona fide medical emergencies, scientific research, management and financial audits, and program evaluation, or upon court order based on a showing of good cause. ${ }^{252}$ Subsection (c) specified that "[e]xcept as authorized by a court order granted under subsection (b)(2)(C), no record referred to in subsection (a) may be used to initiate or substantiate any criminal charges against a patient or to any investigation of a patient." 253 Subsection (d) specified that the prohibitions on disclosure continue after a person is no longer a patient. 254

The statute has been amended multiple times over the years. $^{255}$ In 1992, the Alcohol, Drug Abuse, and Mental Health Administration (ADAMHA) Reorganization Act, ${ }^{256}$ broadened the applicability of the confidentiality protection from "alcoholism and alcohol abuse" programs to "substance abuse." Today this confidentiality provision is in the U.S. Code at 42 U.S.C. $\S 290(\mathrm{dd})-2 .{ }^{257}$

The regulations define "patient identifying information" as "name, address, social security number, fingerprints, photograph, or similar information by which the identity of a patient can be determined with reasonable accuracy and speed either directly or by reference to other publicly available information." 258 They further explain that the restrictions on disclosure apply to "any information [obtained by a federally assisted substance abuse program for treatment purposes] ... which ... [w]ould identify a patient as an alcohol or drug abuser either directly, by reference to other publicly available information, or through verification of such an identi-

$\S 408,86$ Stat. 66,79 .

252. Id.

253. $I d$

254. Id.

255. For example, there were changes to names, effective dates, and other technical changes in 1974 through Pub. L. No. 93-282, § 303(a), (b), 88 Stat. 137, 138 (1974) and in 1976 through Pub. L. No. 94-237, § 4(c)(5)(A), 90 Stat. 244 (1976) and Pub. L. No. 94-581, § 111(c)(3), 90 Stat. 2852 (1976). The most pertinent changes for our purposes are as follows: In 1983, Pub. L. No. 98-24, $\S 2$ (b)(16)(B), 97 Stat. 182 (1983) (codified as 21 U.S.C. § 1175) was transferred to 42 U.S.C. $\S 290$ ee-3. The section was again redesigned in 1987 by Pub. L. No. 100-77, 101 Stat. 516 to 42 U.S.C. $§ 290 d d-2$, where it resides today.

256. ADAHMA Reorganization Act of 1992, Pub. L. No. 102-321, 106 Stat. 323,368 (codified as amended in scattered sections of 42 U.S.C.).

257. 42 U.S.C. $\$ 290 d d-2$ (2006).

258. 42 C.F.R. $§ 2.11$ (2011). 
fication by another person." 259

While the regulations explicitly exempt the restrictions on disclosure for reporting suspect child abuse or neglect, they go on to provide that " $[\mathrm{h}]$ owever, the restrictions continue to apply to the original [substance abuse] patient records maintained by the program including their disclosure and use for civil or criminal proceedings which may arise out of the report of suspected child abuse and neglect." 260 The regulations also make clear that the protected information can only be used as specified by the regulations and "may not otherwise be disclosed or used in any civil, criminal, administrative, or legislative proceedings conducted by any Federal, State, or local authority."261 They further specify that "[a]ny answer to a request for disclosure of patient records which is not permissible under these regulations must be made in a way that will not affirmatively reveal that an identified individual has been, or is being diagnosed or treated for [substance abuse]."262 The regulations also make clear that, if disclosure is prohibited by the regulations, "no State law may either authorize or compel" such disclosure. 263 Interestingly, the regulations also address concurrent coverage under the substance abuse records and the Certificate's protections and notes that "a court order authorizing a disclosure of information about a patient [under these regulations] does not affect the exercise of authority under [the Certificate]."264 The regulations also specify the procedures and criteria for court orders authorizing disclosure under the regulations. ${ }^{265}$

Case interpretation. The earlier version of the records protection was at issue in Anastasi v. Moregenthau. ${ }^{266}$ In July, 1975, a patient at a New York state drug rehabilitation center made statements to Anastasi, a narcotics parole officer at the center, about her involvement in a murder that the New York City Policy Department was then investigating. 267 At Anastasi's request, she repeated the statements before other parole of-

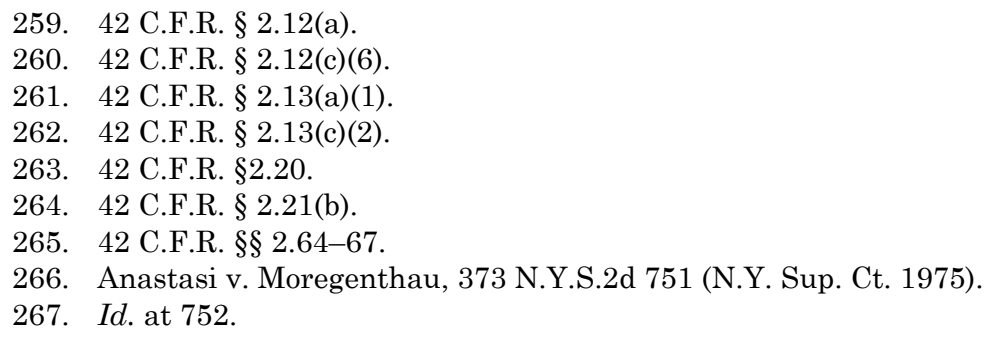


ficers who, at her request, notified the police. ${ }^{268}$ Later, the patient confessed to a homicide detective and an assistant district attorney her complicity in the murder with another, whom she named as the actual killer. 269 The patient agreed to testify before the grand jury and cooperate in the prosecution of the killer in exchange for permission to plead guilty to a lesser charge. 270 Subsequently, her attorney determined that her initial statements actually exculpated her, and he and the patient refused to continue their cooperation with the prior arrangement. ${ }^{271}$ The prosecutor then issued subpoenas to the parole officers who heard the initial statements. ${ }^{272}$

The parole officers moved to quash the subpoenas based on the protections afforded to drug treatment records under 21 U.S.C. $\S 1175 .{ }^{273}$ The court compelled the parole officers to appear before the grand jury because it found that their testimony did not constitute "records of the identity, diagnosis, prognosis, or treatment." 274 It concluded that the protection did not extend to a "gratuitous confession of criminal activity," which was "unrelated to "identity, diagnosis, prognosis, or treatment." 275

The court distinguished the case from People v. Newman, because, unlike in Newman, the identity of the patient and her status as a patient was known-indeed, the patient herself had "repeatedly revealed and discussed it with the police and prosecutors." 276 The court also found that the patient had waived her right of confidentiality by her express request that parole officers disclose her statements to the police, her repetition of her statement to authorities, and her discussion with those authorities of her conversations with petitioners. ${ }^{277}$

\section{Protection of Federal Research Data}

In addition to the topic-specific statutory protections that were enacted based on similar concerns that created the Certif-

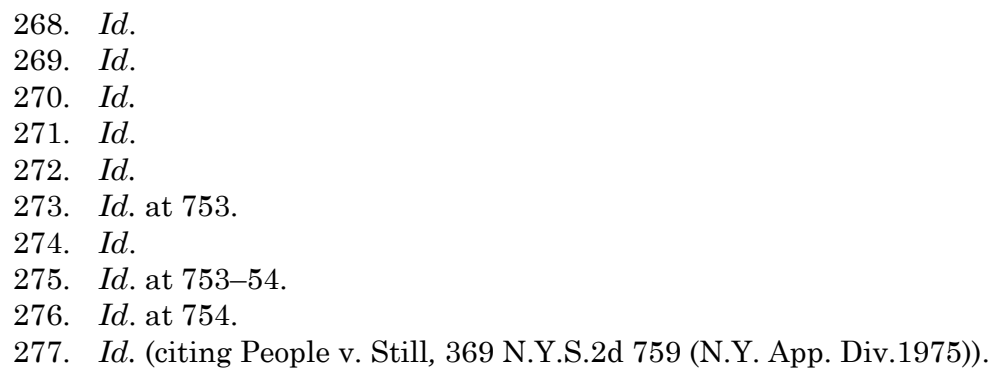


icate protections, there are several federal statutes that protect data for research that is conducted by the federal government or on behalf of the federal government. ${ }^{278}$

Department of Justice (42 U.S.C. $\&$ 3789g). 42 U.S.C. $\S 3789 \mathrm{~g}$ protects confidentiality of records related to justice system improvement. It provides:

No officer or employee of the Federal Government, and no recipient of assistance under the provisions of this chapter shall use or reveal any research or statistical information furnished under this chapter by any person and identifiable to any specific private person for any purpose other than the purpose for which it was obtained in accordance with this chapter. Such information and copies thereof shall be immune from legal process, and shall not, without the consent of the person furnishing such information, be admitted as evidence or used for any purpose in any action, suit, or other judicial, legislative, or administrative proceedings. ${ }^{279}$

Similar confidentiality provisions first appeared in 42 U.S.C. $§ 3771.280$ The Chapter was revised in 1979, resulting in the current section. ${ }^{281}$ There have been few cases interpreting the protections, although there are a number of Ohio cases that authorize withholding records from production because of the statute's protections. ${ }^{282}$

278. In this section, we identify three separate protections involving different federal entities. Two of these (the DOJ and AHRQ) are mentioned in the frequently asked questions on the NIH Certificate Kiosk. FAQs on Certificates, supra note 1 . The third (CDC) is mentioned in connection with the AHRQ statute. Other federal departments and agencies may offer similar protections for research conducted by and with them. For example, there are limits on use and publication of census information. 13 U.S.C. $§ 9$ (2006). Our discussion is not meant to be exhaustive.

279. 42 U.S.C. $\S 3789 \mathrm{~g}(\mathrm{a})(2006)$.

280. Omnibus Crime Control and Safe Streets Act of 1968, Pub. L. No. 90351, 82 Stat. 197 (1968).

281. Justice System Improvement Act of 1979, Pub. L. No. 96-157, § 818, 93 Stat. 1167, 1213 (1979). For current version, see 42 U.S.C. § 3789g (2006). There have been minor amendments in 1984 and 2006, which did not affect the substance. See Pub.L. No. 98-473, 98 Stat. 1837; Violence Against Women and Department of Justice Reauthorization Act of 2005, Pub. L. No. 109-162, 119 Stat. 2960.

282. See, e.g., State ex rel. Multimedia, Inc. v. Snowden, 647 N.E.2d 1374 (Ohio 1995); State ex rel. Johnson v. City of Cleveland, 603 N.E.2d 1011 (Ohio 1992). But cf. State ex rel. Attorney Gen.v. First Judicial Dist. Court, 629 P.2d 330 (N.M.1981) (stating that investigation documents were not protected because the statute covers records supported by federal funds and federal funds were awarded only after investigation was completed). There are also a number of cases ruling that there is no private right of action for violation of the statute, primarily relying on the analysis in Polchowski v. Gorris, 714 F.2d 
Agency for Healthcare Quality and Research (42 U.S.C. $\S 299 c-3)$. AHRQ provides statutory protection for identifiable information collected by the agency as follows:

(c) Limitation on use of certain information. No information, if an establishment or person supplying the information or described in it is identifiable, obtained in the course of activities undertaken or supported under this subchapter may be used for any purpose other than the purpose for which it was supplied unless such establishment or person has consented (as determined under regulations of the Director) to its use for such other purpose. Such information may not be published or released in other form if the person who supplied the information or who is described in it is identifiable unless such person has consented (as determined under regulations of the Director) to its publication or release in other form. ${ }^{283}$

This statute has not changed since the law was originally passed in 1999 when AHRQ was created. ${ }^{284}$ It replaced an identical statute to protect identifiable information, 42 U.S.C. $\S$ 299a1-(c), passed in 1989 during the creation of AHRQ's predecessor agency, the Agency for Health Care Policy and Research. ${ }^{285}$

There is nothing in the legislative history to expand upon the protections afforded by the AHRQ statute. However, in 2001, AHRQ issued a Memorandum on Statutory Confidentiality Protection of Research Data on its website that describes the AHRQ statute in detail and how it should be interpreted. ${ }^{286}$ As described in the memorandum, AHRQ reads: "this Federal mandate, to keep confidential all identifiable research data collected pursuant to AHRQ's authorizing legislation ... and not to disclose any of this identifiable data without the consent of the supplier of the data or of the subject individuals, as applying to anyone with access to that collected data." 287

The Agency interprets the restrictions of the statute as attaching themselves to "any identifiable research data once it has been collected pursuant to AHRQ-supported programs or

749 (7th Cir. 1983).

283. 42 U.S.C. $\$ 299 c-3(c)(2006)$.

284. Healthcare Research and Quality Act of 1999, Pub. L. No. 106-129, $\S 2(a), 113$ Stat. 1667 (codified as amended in scattered sections of 42 U.S.C. (2006)).

285. Omnibus Budget Reconciliation Act of 1989, Pub. L. No. 101-239, § 6103(a), 103 Stat. 2106, 2189.

286. Memorandum from Susan Greene Merewitz, Senior Attorney, Agency for Healthcare Research \& Quality, to Nancy Foster, Coordinator for Quality Activities, Agency for Healthcare Research \& Quality (Apr. 16, 2001), available at http://www.ahrq.gov/fund/datamemo.htm.

287. Id. 
projects." 288 The terms of the statute are also not timelimited-the obligation of protection does not end, even if the original statute is replaced. 289 The memorandum acknowledges the lack of a legal challenge of the AHRQ statute, but also notes examples of potential legal challenges and that the CDC has taken steps to avoid potential legal problems by negotiating solutions with parties to avoid a violation of its similar statute discussed below. 290

Centers for Disease Control and Prevention (42 U.S.C. $\S 242 \mathrm{~m})$. The CDC provides an Assurance of Confidentiality, which protects identifiable data collected by it:

(d) Information; publication restrictions. No information, if an establishment or person supplying the information or described in it is identifiable, obtained in the course of activities undertaken or supported under section $242 \mathrm{~b}, 242 \mathrm{k}$, or $242 l$ of this title may be used for any purpose other than the purpose for which it was supplied unless such establishment or person has consented (as determined under regulations of the Secretary) to its use for such other purpose; and in the case of information obtained in the course of health statistical or epidemiological activities under section $242 \mathrm{~b}$ or $242 \mathrm{k}$ of this title, such information may not be published or released in other form if the particular establishment or person supplying the information or described in it is identifiable unless such establishment or person has consented (as determined under regulations of the Secretary) to its publication or release in other form. 291

This CDC statute was included in the authorizing statute for the National Center for Health Statistics (NCHS) in 1974. ${ }^{292}$ While there is extensive legislative history pertaining to the creation of the NCHS, the discussion of the confidentiality provisions is limited. A 1978 committee report addressing statutory amendments noted the purpose of these restrictions on disclosure:

The committee is especially concerned about individual rights to privacy and the confidentiality of individual medical records or of any information which might be collected, maintained, published, or released in some other individually identifiable form. It is the committee's intent that any activities conducted under the authority of this act shall be in conformance with section 308(d) of the [PHSA] which protects the confidentiality and privacy of individuals and enti-

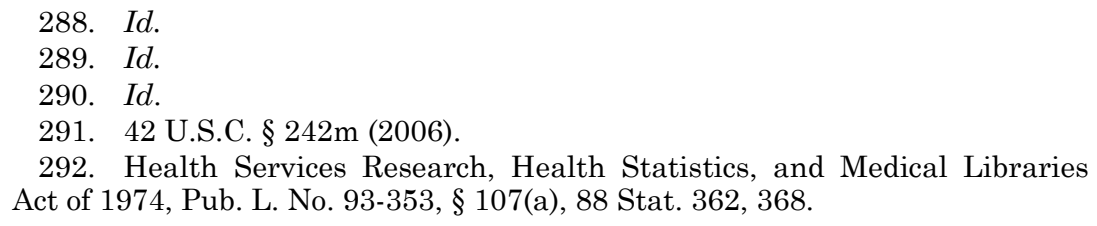


ties which submit data. In addition, the Secretary may not use any information obtained for any other purpose than the purpose for which it was supplied unless the individual or entity is so notified. ${ }^{293}$

Section (d) has been modified three times since the original authorizing statute. In 1978, "statistical or epidemiological activities" was substituted for "statistical activities."294 The statute originally applied to all information collected by the agency, but was modified in 1983, to information "if an establishment or person supplying the information or described in it is identifiable." ${ }^{295}$ Finally, in 1989, $\S \S 242 \mathrm{c}$ and $242 \mathrm{n}$ of the PHSA were removed from the section because both of these statutes were repealed the same year. ${ }^{296}$ The reasons for these changes are not discussed in the congressional reports.

Summary. These statutes differ from the Certificate authorizing statute in a couple of important ways. First, they do not require that a researcher apply for the protections. Rather, the protections attach to all research within the scope of the statute. Second, they apply to all of the data collected, not just identifiable data. Accordingly, this avoids some of the problems arising with data that is not identifiable, but may, when coupled with other information, be identifying.

\section{B. STATE STATUTES}

A number of states have adopted statutes to protect research data from compelled disclosure. Some of these statutes are similar to the AHRQ, CDC, and DOJ statutes described in Part III.A above, in that they broadly protect data from research conducted by or for a state agency. For example, Maryland's statute protects records "assembled or obtained for research or study" 297 in the custody and control of "(i) The Drug Abuse Administration, if that administration assembled or obtained the confidential record; (ii) The AIDS Administration, if that Administration assembled or obtained the confidential record; or (iii) The Secretary or an agent or employee of the

293. S. REP. 95-839, 12, reprinted in 1978 U.S.C.C.A.N. 9088, 9099.

294. Health Services Research, Health Statistics, and Health Care Technology Act of 1978, Pub. L. No. 95-623, §§ 2, 6(d), 8(b), 92 Stat. 3443, 3451, 3455 .

295. Orphan Drug Act, Pub. L. No. 97-414, § 8(c), 96 Stat. 2049, 2060 (1983).

296. Omnibus Budget Reconciliation Act of 1989, Pub. L. No. 101-239, $\S 6103(\mathrm{e})(4), 103$ Stat. 2106, 2206.

297. MD. CoDE. ANN., Health-General § 4-101, 72 (LexisNexis 2009). The records must also name or "otherwise identif[y] any person." Id. 
Secretary, if the Secretary assembled or obtained the confidential record" and limits use "only for the research and the study for which it was assembled or obtained" and disclosure "to any person who is not engaged in the research or study project." 298 The statute does permit publication of information "that summarizes or refers to confidential records in the aggregate, without disclosing the identity of any person who is the subject of the confidential record."299 A Maryland appeals court held that the department could not withhold the identity of a restaurant from which the requester may have acquired Hepatitis A under this statute. ${ }^{300}$ The case turned on whether a "case investigation" of Hepatitis transmission constituted "research" or a "study" under the statute.301 The court ultimately concluded that the Department erred in denying the individual's entire request under the statute, but recognized that some records might be protected under this and another statute. 302 At no point did the court question that the Department could protect research records, as provided under the statute.

Similarly, North Dakota protects

all information, records of interviews, written reports, statements, notes, memoranda, or other data procured by the state department of health, in connection with studies conducted by the state department of health, or carried on by the department jointly with other persons, agencies, or organizations, or procured by such other persons, agencies, or organizations, for the purpose of reducing the morbidity or mortality from any cause or condition of health [providing that they are] confidential and must be used solely for the purposes of medical or scientific research. ${ }^{303}$

The statute further provides that the protected information "is not admissible as evidence in any action of any kind in any court or before any other tribunal, board, agency, or person," although data may be disclosed as necessary "for the purpose of furthering the research project to which they relate." 304

South Dakota protects "[a]ll information, interviews, re-

298. MD. CoDE. ANN., Health-General § 4-102(a), 72 (LexisNexis 2009).

Similar provisions were originally enacted in 1963. Haigley v. Dep't of Health \& Mental Hygiene, 736 A.2d 1185, 1197 (Md. Ct. Spec. App. 1999).

299. MD. CoDE. ANN., Health-General § 4-102(b) (LexisNexis 2009).

300. Haigley, 736 A.2d at 1203.

301. Id. at $1187-88$.

302. Id. at 1203.

303. N.D. CENT. CODE $§ 23-01-15(1)$ (2012).

304. N.D. CENT. CODE $§ 23-01-15(2)$ (2012). 
ports, statements, memoranda, or other data procured by the Department of Health, South Dakota State Medical Association, allied medical societies, or in-hospital staff committees of accredited hospitals in the course of a medical study for the purpose of reducing morbidity or mortality," providing that such information "shall be strictly confidential and shall only be used for medical research."305 It further provides that "[s]uch information... shall not be admissible as evidence in any action of any kind in any court or before any tribunal, board, agency, or person." 306 Washington generally protects research records, providing that

[n]o research professional who has established an individually identifiable research record from personal record information ... or who has established a research record from data or information voluntarily provided by an agency client or employee under a written confidentiality assurance for the explicit purpose of research, may disclose such a record in individually identifiable form unless:

1) the person or his or her legally authorized representative consents; 2) disclosure is necessary to prevent or minimize injury, only the information necessary to protect is disclosed, and the disclosure is limited to select people; 3) for audit purposes authorized by law; or 4) pursuant to a search warrant or court order. ${ }^{307}$ The latter is limited to circumstances where the record will be used

solely for the purpose of facilitating inquiry into an alleged violation of law by the research professional using the record for a research purpose or by the agency; and ... [a]ny research record obtained [by warrant or order] and any information directly or indirectly derived from the research records shall remain confidential to the extent possible and shall not be used as evidence in an administrative, judicial, or legislative proceeding except against the research professional using the record for a research purpose or against the state agency. ${ }^{308}$

On the other hand, other states have adopted protections that are specific to certain types of research, rather than research conducted by or for a particular state agency. The topics tend to be for research involving potentially stigmatizing conditions, such as mental health, HIV/AIDS, and genetics. For ex-

305. S.D. CODIFIED LAWS $§ 34-14-1$ (2011). The state's authority to protect some state records, including this protection of medical research records, was noted in Doe v. Nelson, 680 N.W.2d 302, 310 n.9 (S.D. 2004) (holding that the Governor did not have authority to seal pardons granted directly by the Governor).

306. S.D. CODIFIED LAWS $\S 34-14-1$ (2011).

307. WASH. REV. CODE ANN. § 42.48.040 (West 2006).

308. Id. 


\section{ample, Hawaii provides that}

[a]ny findings, conclusions, or summaries resulting from medical studies within the scope of [mental health and mental retardation studies] shall not be used or made available in any legal proceeding. Any information provided to any research or study committee shall not be used or made available in any legal proceeding unless it is unobtainable from the original source. In such event, the judicial officer shall in chambers inspect the committee's findings, conclusions, or summaries and make available factual information contained therein. ${ }^{309}$

California provides that

[r]esearch records, in a personally identifying form, developed or acquired by any person in the course of conducting research or a research study relating to HIV or AIDS shall be confidential, and these confidential records shall not be disclosed by any person in possession of the research record, nor shall these confidential records be discoverable, nor shall any person be compelled to produce any confidential research record, except as provided by this chapter. ${ }^{310}$

Arkansas and Oklahoma prohibit disclosure of data from genetic research. ${ }^{311}$ Specifically, the Arkansas statute provides that

(a) No research records of individual subjects in genetic research studies shall be: (1) Subject to subpoena or discovery in civil suits, except in cases in which the information in the records is the basis of the suit; or (2) Disclosed to employers or health insurers without the informed, written consent of the individual. ${ }^{312}$

The statute allows for disclosure of stored tissue for research studies with the patient/participant's consent, if identified by name or social security number, or without consent, if not identified by name or social security number, and for publication of results with similar restrictions. ${ }^{313}$ The Oklahoma "Genetic Research Studies Nondisclosure Act" provides that

[a]ll research records of individual subjects in genetic research studies shall be confidential, meaning the records shall not be subject to subpoena or discovery in civil suits, except in cases where the information in the records is the basis of the suit. The records shall not be disclosed to employers or health insurers without the informed con-

309. HAW. REV. STAT. § 324-13 (West 2008).

310. CAL. HEALTH \& SAFETY CODE $§ 121075$ (West 2012). The statute was amended in 2006 to change the scope from AIDS to HIV and AIDS research. 2006 Cal. Legis. Serv. Ch. 20 (West).

311. ARK. CODE. ANN. § 20-35-103 (LexisNexis 2005); OKLA. STAT. tit. 36, § 3614.4 (2011).

312. ARK. CODE. ANN. § 20-35-103(a) (LexisNexis 2005).

313. ARK. CODE. ANN. § 20-35-103(b), (c) (LexisNexis 2005). 
sent of the subject. 314

Like the Arkansas statute, the Oklahoma statute permits tissues to be used for research with consent and allows publication without identification or with consent if the subject will be identified. ${ }^{315}$ The statute also permits disclosure for life, disability income, or long-term care insurance and legal proceedings related to such insurance. ${ }^{316}$

New Mexico's protection is most similar to the Certificate's protections, allowing its pharmacy board to

authorize persons engaged in research on the use and effects of controlled substances to withhold the names and other identifying characteristics of individuals who are subjects of the research. Persons who obtain this authorization are not compelled in any civil, criminal, administrative, legislative or other proceedings to identify the individuals who are the subjects of research for which the authorization was obtained. ${ }^{317}$

It further provides that

[a] practitioner engaged in medical practice or research shall not be required to furnish the name or identity of a patient or research subject to the board, nor may he be compelled in any state or local civil, criminal, administrative, legislative or other proceedings to furnish the name or identity of an individual that the practitioner is obligated to keep confidential. ${ }^{318}$

In revising its evidence code in 2011, Georgia adopted protections for research data. In doing so, the legislature declared that "confidentiality of research data from disclosure in judicial and administrative proceedings is essential to safeguarding the integrity of research ... guaranteeing the privacy of individuals who participate in research projects, and ensuring the continuation of research in science, medicine and other fields that benefits the [public]." 319 "[C]onfidential raw research data" is defined as:

medical information, interview responses, reports, statements, memoranda, or other data relating to the condition, treatment, or characteristics of any person which are gathered by or provided to a researcher:

314. OKLA. STAT. tit. $36, \S 3614.4$ (c) (2011).

315. OKLA. STAT. tit. 36, § 3614.4(e) (2011).

316. OKLA. STAT. tit. 36, § 3614.4(d) (2011).

317. N.M. STAT. ANN. § 30-31-40(B) (West 2003).

318. N.M. STAT. ANN. §30-31-40(D) (West 2003). There are some cases that cite to this statute, but they involve constitutional challenges to the drug paraphernalia laws generally, rather than the confidentiality protections specifically. See, e.g., Weiler v. Carpenter, 507 F.Supp. 837, 839 (D. N.M. 1981); State v. Carr, 626 P.2d 292, 294 (N.M. Ct. App. 1981); Chouinard v. State, 635 P.2d 986, 986 (N.M. Ct. App. 1980).

319. GA. CODE ANN. § 24-12-2(a) (West 2011). 
(1) In support of a research study approved by an appropriate research oversight committee of a hospital, health care facility, or education institution; and (2) with the objective to develop, study, or report aggregate or anonymous information not intended to be used in any way in which the identify of an individual is material to the results. ${ }^{320}$

Such data "shall not be subject to subpoena, otherwise discoverable, or deemed admissible as evidence in any judicial or administrative proceeding." 321 However, there are several exceptions to this protection. These include common exceptions, such as disclosure to the subject or the subject's legally authorized representative or to someone authorized in writing by the individual or her legally authorized representative to receive it, a government entity when required to be reported by law (e.g., communicable disease or child abuse reporting), and in a proceeding where the research participant places his or her involvement in the study at issue. ${ }^{322}$ However, the protections do not apply when "the researcher has either volunteered to testify or has been hired to testify." 323 Moreover, the protections seem to disappear in criminal proceedings, as the statute provides that "the court shall order the production of confidential raw research data if the data are relevant to any issue in the proceeding... and admit confidential raw research data into evidence if the data are material to the defense or prosecution," although the court must also "impose appropriate safeguards against unauthorized disclosure of the data." 324

One of the strengths of these statutes, compared to the Certificate statute, is that, with the exception of the New Mexico statute, ${ }^{325}$ the protection attaches to all research within the statute's scope, either by topic or under the aegis of the state entity; the protection does not require a researcher to know about and apply for it. In some cases, the protection afforded is stronger than that which the Certificate offers. ${ }^{326}$ For example,

320. GA. CODE ANN. § 24-12-2(b) (West 2011).

321. GA. CODE ANN. § 24-12-2(c) (West 2011).

322. GA. CODE ANN. § 24-12-2(d) (West 2011).

323. GA. CODE ANN. § 24-12-2(d)(6) (West 2011).

324. Id.

325. N.M. STAT. ANN. § 30-31-40(D) (West 2003).

326. On the other hand, some state statutes may be less protective than the Certificate. For example, Georgia's statute appears to eliminate participants' protections when researchers' act as experts and in the context of all criminal proceedings. GA. CODE ANN. § 24-12-2 (West 2011). 
the Maryland, North Dakota, and South Dakota statutes explicitly limit the use of the data for purposes other than research. ${ }^{327}$ In addition, these statutes refer to any disclosure, not just compelled disclosure. ${ }^{328}$ Similarly, the Arkansas and Oklahoma statutes allow disclosure for litigation only if the data form the basis of the claims. ${ }^{329}$ Several of these do not appear to be limited to identifiable information, even though they may permit publication of aggregate information.

Although these laws have important strengths compared to a Certificate, they may ultimately be less protective because, as state laws, they may not be able to prevent disclosure where federal law permits or even requires the disclosure.

\section{OTHER AVAILABLE PROTECTIONS}

Our interviews with counsel and our review of the cases suggests that there are a variety of legal tools beyond Certificates that can be used to try to protect sensitive, identifiable data from compelled disclosure. While a discussion of all other potential ways to protect sensitive research data from compelled disclosure is beyond the scope of this paper, in this section, we provide a brief overview of some of these tools that may supplement a Certificate's protections. 330

First, our interviews and the cases serve as a reminder of the general discovery tools that are available when research data are subpoenaed. Counsel can, and should (where appropriate), object to demands, for example, on the grounds of relevance, materiality, breadth, and burden. ${ }^{331}$ Objections can form the basis for negotiating limits on the subpoena, such as excluding identifiers, or, if necessary, for moving to quash the subpoena. ${ }^{332}$ As noted earlier, counsel frequently are successful

327. MD. Code. ANN., Health-General § 4-101, 72 (LexisNexis 2009); N.D. CENT. CODE § 23-01-15 (2012); S.D. CODIFIED LAWS § 34-14-1 (2011).

328. MD. CoDE. ANN., Health-General § 4-101, 72 (LexisNexis 2009); N.D. CENT. CODE § 23-01-15 (2012); S.D. CODIFIED LAWS § 34-14-1 (2011).

329. ARK. CODE. ANN. § 20-35-103 (LexisNexis 2005); OKLA. STAT. tit. 36, § 3614.4 (2011).

330. For a more in-depth discussion of how to address subpoenas for scholarly research, see Michael Traynor, Countering the Excessive Subpoena for Scholarly Research, 59 LAW \& CONTEMP. PROBS. 119 (1996).

331. Id. at 126. See also FED. R. Civ. Pro. 45; 9A Charles A. Wright \& Arthur R. Miller, Federal Practice \& Procedure $§ 2007$ (3d ed. 2012).

332. Traynor, supra note 330 , at 126 . 
in limiting requests using these types of tools. If disputes do go to court, then it would be appropriate to request a protective order. ${ }^{333}$ As our case examples demonstrate, the protective order can be used not only to limit disclosure of identifiable components of data, but also to limit who has access to the data and how it can be used (e.g., limited to the lawsuit in which it was subpoenaed), forbid attempts to reidentify, and require destruction of data held by the requesting party when the litigation ends.

Second, some counsel have been successful in protecting data based on First Amendment claims and/or a researcher's privilege, a concept akin to a reporter's privilege. These claims have been particularly successful when the data has not yet been published, recognizing the researchers' interests in the fruits of their labor and in choosing how and when to publish it. ${ }^{334}$ An example is the case of Cusumano v. Microsoft Corp. ${ }^{335}$ In this case, Microsoft sought a researcher's "notes, tape recordings and transcripts of interviews, and correspondence with interview subjects" pertaining to interviews with Netscape employees about its battle with Microsoft over search engines. ${ }^{336}$ At the time the interviews were conducted, Microsoft had not yet been sued for the antitrust violations that caused them to seek the data. ${ }^{337}$ The case study had not yet been published when Microsoft subpoenaed the data. ${ }^{338}$ The court concluded that "[a]cademicians engaged in pre-publication research should be accorded protection commensurate to that which the law provides for journalists." 339 It reasoned "scholars [like journalists] are information gatherers and disseminators" 340 and require protection to avoid a "chilling effect on free speech." 341 In the particular circumstances, the researchers had made assurances to interviewees that their information would be kept confidential and that they would have an opportunity to "cor-

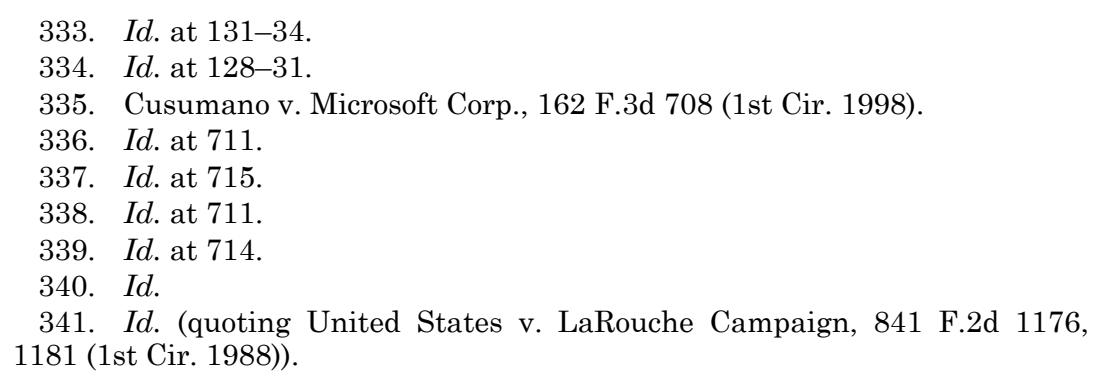


rect, comment upon, and/or disclaim attributed quotations prior to publication." 342 Accordingly, the First Circuit agreed with the lower court that "the interviews ... fall along the continuum of confidentiality at a point sufficient to justify significant protection" 343 and, that the movant's need for the information was outweighed by the respondent's need for protection. ${ }^{344}$

\section{DISCUSSION}

As the above discussion demonstrates, Certificates of Confidentiality and other confidentiality statutes and legal doctrines can be effective tools for protecting sensitive, identifiable human subjects research data. However, those protections can be vulnerable to judicial interpretation. In particular, we found two areas in which there have been problematic judicial decisions that interpret the Certificate protection in ways that undermine those protections: waiver and identifiability. In this section, we examine how waiver and identifiability have been treated in other legal contexts for suggestions on how to address the concerns in the context of Certificates. We then consider steps that could be taken to minimize Certificates' vulnerabilities we have identified through our analysis.

\section{A. WAIVER OF CONFIDENTIALITY PROTECTIONS}

It is not surprising that individual participants may waive the confidentiality protections afforded by the Certificate and some of the related statutes we have discussed. The protections are intended to benefit the individual by maintaining confidentiality, so when circumstances arise, such as that experienced by Mr. Still, where that confidentiality may disadvantage the individual, he should be able to waive confidentiality. However, the Juvenile Court case raises important questions about what constitutes waiver in this context. Unlike the Still case, where the defendant made a specific (and written) request that identifiable information about him to be disclosed, in the Juvenile Court case, the researchers certainly did not intend to waive

342. Id. at 715 .

343. Id.

344. Id. at 716-17. Importantly, the court commented on the procedures the researchers adopted as evidence of the need for protection. Traynor provides an excellent discussion of what steps researchers should take in their data collection that would also evidence the importance of confidentiality to their research to a court should it be necessary. Traynor, supra note 330, at $121-25$. 
the protections by reporting their suspicions of child neglect. Waiver of such important protections should not result from inadvertent disclosure, nor should disclosure for one purpose (e.g., protection from abuse or neglect) result in disclosure for all purposes. Such a broad interpretation is inconsistent with how the law treats waiver of confidentiality in other context.

Considering how courts address waiver of confidentiality for medical records is useful to our inquiry for several reasons. First, much (but not all) sensitive research data is healthrelated and, thus, the rationale for protecting it is similar to that of medical records. ${ }^{345}$ Second, the protection for medical records generally is statutory, like the Certificate, although there often are many exceptions to the statutory protections, especially compared to the Certificate language. Finally, there may be some circumstances in both contexts, such as abuse and neglect reporting, where there may be strong reasons for revealing some information, and where we do not want a disincentive to disclosure, such as waiving all protection. Thus, there are many similarities between the protections afforded to medical records and Certificates and, given the lesser protections afforded to medical records (in that there are greater statutory exceptions), the limitations applied to waiver in that context suggest waiver would be found less frequently in the context of the more absolute protections afforded by the Certificate. ${ }^{346}$

One common example where the law finds an individual waives physician-patient confidentiality is when that individual brings a suit against the physician for medical malpractice. The doctor can only defend himself if he is allowed to put forward information about his treatment of the patient from the medical record. However, the central legal question for courts is the scope of the waiver; that is, what components of the pa-

345. Indeed, while we often consider only the individual's interest in the confidentiality of their medical records, benefit to others (the primary justification for research) is an important part of the justification for protecting patient confidentiality. Such confidentiality encourages patients to share accurate information about sensitive, communicable diseases, and permits doctors and public health authorities to take action to prevent disease in others.

346. An important difference between medical records and research records protected by a Certificate is that medical care is undertaken for personal benefit, whereas research-even where there is the hope of therapeutic benefit-is undertaken to benefit others. This adds another reason for affording stronger protections to the research data. 
tient's health have been placed "at issue." In bringing suit for a faulty knee replacement at age fifty-five, a patient likely does not expect or intend to place her entire medical history open for examination, nor does the doctor likely need access to that whole history to defend himself. In considering whether health has been placed in issue, courts have looked to relevancy and specificity as the guiding principles. For example, in Davis $v$. Superior Court, a motorist brought a personal injury action seeking general damages for pain and suffering. ${ }^{347}$ The defendant sought the motorist's psychotherapy records but was denied by the lower court. ${ }^{348}$ In upholding the decision, the appellate court stated that the "materials sought must be directly relevant to the issue of pain and suffering associated with the physical injuries sustained." 349 A "garden-variety" claim of pain and suffering did not place the motorist's mental health in issue, notwithstanding the mental component of the claim. ${ }^{350}$ The Davis court further noted that "the scope of [the waiver necessary for such suits] must be narrowly, rather than expansively, construed, so that plaintiffs will not be unduly deterred from instituting lawsuits by fear of exposure of private activities." 351 Similarly, in In re Marriage of Bonneau, the court found that a husband in a divorce proceeding did not place his health in issue by filing for dissolution on the ground of mental cruelty. 352 The wife sought the husband's HIV-related medical records, but the court stated that his health would only have been in issue if the husband's grounds for dissolution were that his wife infected him with HIV. ${ }^{353}$ The husband had not "specifically or affirmatively placed his health in issue in the pleadings." $354 \mathrm{~A}$ 2010 Georgia case reiterated the need to construe any waiver of confidentiality to medical information "with narrow specifici-

347. Davis v. Superior Court, 9 Cal. Rptr. 2d 331, 332-33 (Cal. Ct. App. 1992).

348. Id. at 333 .

349. Id. at 337.

350. Id.

351. Id. at 335 (citing Vinson v. Superior Court, 740 P.2d 404 (Cal. 1987)). The court concludes "[t]he scope of any disclosure must be narrowly circumscribed, drawn with narrow specificity, and must proceed by the least intrusive manner." Id. (citing Binder v. Superior Court, 242 Cal. Rptr. 231, 234 (Cal. Ct. App. 1987)).

352. In re Marriage of Bonneau, 691 N.E.2d 123 (Ill. App. Ct. 1998).

353. Id. at 132 .

354. Id. 
ty." 355

Cases seeking access to HIV-related information, like In re Marriage of Bonneau, provide additional insight into the issue of waiver of confidentiality protection. Because of the serious stigma and discrimination concerning HIV/AIDS early in the epidemic and continuing today, nearly every state has passed an HIV confidentially act. When testing first became available, there were few individual benefits to testing and significant risks. Strict confidentiality protections were adopted to encourage individuals to be tested. As illustrated by Doe v. City of New York, the protections can extend beyond medical records. ${ }^{356}$ Doe involved a single, HIV-positive man who filed a complaint against Delta Airlines with the City of New York Commission on Human Rights, alleging he was not hired because of his sexual orientation and suspicion about his HIV status. ${ }^{357}$ After reaching a settlement between the parties, and without Doe's permission, the Commission issued a press release disclosing the terms of the settlement agreement, despite a confidentiality clause in the settlement agreement. 358 Although the press release did not identify Doe by name, Doe contended that it violated his privacy because people who knew or worked with Doe could identify him from the information included.359 The district court dismissed Doe's suit against the Commission for this breach of privacy, concluding that any right of privacy Doe possessed had been waived when he originally brought a discrimination suit against Delta, because it was a matter of public record and the Commission had a right

355. Baker v. Wellstar Health System, Inc., 703 S.E.2d 601, 604-05 (Ga. 2010). In this case, the plaintiff sued Wellstar for malpractice. Pursuant to Health Insurance Portibility and Accountability Act (HIPPA), defense counsel was granted a qualified protective order to conduct ex parte interviews of the plaintiff's treating physicians. In an interlocutory appeal, the court found that although HIPAA preempted Georgia law with regard to ex parte communications between defense counsel and plaintiff's prior treating physicians, the substantive right to medical privacy under Georgia law endured. Thus the court found the qualified protective order "too broad regarding the scope of information that may be disclosed." Rather than allowing discussion of "medical conditions and any past, present, or future care and treatment... the order should have limited Wellstar's inquiry to matters relevant to the medical condition . . . at issue." Id. at 604.

356. Doe v. City of NY., 15 F.3d 264, 267 (2d Cir. 1994).

357. Id. at 265.

358. Id.

359. Id. 
to disseminate the results of the agreement. 360 The appellate court reversed the district court. 361 After determining that Doe did have a right to privacy in his HIV status, ${ }^{362}$ the court addressed the question of whether he waived that right when he filed a claim with the Commission. ${ }^{363}$ Although all conciliation agreements were made public record by statute, the statute permitted the Commission to agree not to disclose. 364 The court noted the "Orwellian" nature of the Commission's position that Doe had waived any privacy rights concerning his claim when the Commission is charged with protecting privacy rights. 365 While the court conceded that Doe might not prevail, it refused to find a waiver of confidentiality protections on such general grounds. ${ }^{366}$

Given the ease with which the Juvenile court found waiver in its case involving a Certificate, it is also useful to consider how courts have addressed inadvertent disclosure of confidential information. While the disclosure of the children's identities cannot be said to have been "inadvertent"-the researchers certainly intended to convey their concerns about the children to the Department of Children and Families - the waiver of the protection (as determined by the court) certainly can be. Yale's motion to quash makes clear the researchers did not intend to give up the protections afforded by the Certificate. ${ }^{367}$ From the court's interpretation of waiver, it is not difficult to imagine a case where a researcher's response, "I cannot give you Jane Doe's records. She is in a research study protected by a Certifi-

360. Id. at 266 .

361. Id. at 270 .

362. Id. at 267. In so holding, the court noted that

[e]xtension of the right to confidentiality to personal medical information recognizes there are few matters that are quite so personal as the status of one's health and few matters the dissemination of which one would prefer to maintain greater control over. Clearly, an individual's choice to inform others that she has contracted what is at this point invariably and sadly a fatal incurable disease is one that she should normally be allowed to make for herself.

$I d$. This protection of a medical condition is not available to all conditions, however. In Matson v. Bd. of Educ. of the City Sch. Dist. of N.Y., the court refused to recognize fibromyalgia as falling within the ambit of constitutionallyprotected privacy. Matson v. Bd. of Educ. of the City Sch. Dist. of N.Y., 631 F.3d 57, 69 (2d Cir. 2011).

363. Doe, 15 F.3d at 267-69.

364. Id. at 268 .

365. Id.

366. Id. at 269-70.

367. Memorandum of Decision, supra note 198, at 2. 
cate," is interpreted as a waiver of the protections because the researcher confirmed the person is a participant in the study.

We found that cases of inadvertent waiver typically come up in the context of document productions. Courts have taken a variety of approaches in considering whether the inadvertent disclosure constitutes a waiver. At one end of the spectrum, a minority of courts take a strict approach. These courts view the inadvertent disclosure of any protected information as resulting in an automatic waiver of the privilege pertaining to that information and sometimes any related information of the same subject matter. ${ }^{368}$ As noted by the court in the leading strict liability approach case, "we do not think it matters whether the waiver is labeled 'voluntary' or 'inadvertent' [disclosure]," 369 for the court, the critical fact was the disclosure. The waiver can be viewed broadly under the strict approach. For example in S.E.C. v. Microtune, Inc., the court held that the privilege had been waived as to all documents related to a corporation's internal investigation of alleged Security and Exchange Commission violations, even though the corporation had disclosed only some of the documents related to the internal investigation to third parties. ${ }^{370}$

At the other end of the spectrum, lies another minority approach, in which courts employ an intent-based approach. Under this approach, an inadvertent disclosure is deemed to be a waiver only when the party asserting the privilege did not intend to maintain confidentiality. For example, in Heriot v. Byr$n e$, a document vendor accidentally produced attorney-client privileged documents to the defendant. ${ }^{371}$ Although the defendants argued that privilege had been waived, the court focused on the plaintiff's actions after the production, rather than the fact a significant portion of documents had been produced, to determine the privilege had not been waived. ${ }^{372}$ In Heriot, the plaintiff had taken clear actions to mitigate the inadvertent

368. Importantly, "[t]he attorney-client privilege is waived if the holder of the privilege voluntarily discloses or consents to disclosure of any significant part of the communication to a third party or stranger to the attorney-client relationship." Memorandum of Opinion and Order at 7-8, Jacob v. DuaneReade, Inc., No. 1:11-cv-00160-JPO-THK (S.D.N.Y. Feb. 28, 2012).

369. In re Sealed Case, 877 F.2d 976, 980 (D.C. Cir. 1989).

370. S.E.C. v. Microtune, Inc., 258 F.R.D. 310, 317 (N.D. Tex. 2009).

371. Heriot v. Byrne, 257 F.R.D. 645, 651 (N.D. Ill. 2009).

372. Id. at 659 . 
disclosure, including contacting the defendants and identifying the privileged documents that had mistakenly been produced. ${ }^{373}$

The majority of courts take a more nuanced approach to inadvertent waiver, the so-called "middle" approach, and, after determining the disclosure was in fact inadvertent, weigh a variety of factors in determining whether a privilege has been waived, including the steps taken to prevent disclosure, the extent, frequency, and circumstances of disclosure, and postdisclosure efforts, as well as "the overriding interest of fairness and justice." 374 This analysis is usually a fact-intensive inquiry into the circumstances surrounding the disclosure. ${ }^{375}$ In addition to being adopted by a majority of courts, the middle road approach was adopted by the Federal Rules of Evidence (FRE) 502(b) in 2008 for use in federal proceedings. ${ }^{376}$ Although FRE 502(b) uses only two of the factors described by courts (reasonable precautions to prevent inadvertent disclosure and the promptness of measures taken to rectify the disclosure), the advisory committee's note states the rule is "flexible enough to accommodate any of those listed factors." 377

The foregoing analysis suggests that there is significant legal support for limiting access to data even where some protections have been waived either by the participant or the researcher, provided that the researcher takes appropriate steps to protect the security of the data. ${ }^{378}$ Nevertheless, given the

373. Id.

374. Elizabeth King, Waving Goodbye to Waiver? Not So Fast: Inadvertent Disclosure, Waiver of the Attorney-Client Privilege, and Federal Rule of Evidence 502, 32 CAMPBELL L. REV. 467, 481-84 (2010).

375. See, e.g., Ciba-Geigy Corp. v. Sandoz Ltd., 916 F. Supp. 404, 411 (D.N.J. 1995) (finding disclosure was not inadvertent given the party seeking protection failed to take reasonable precautions in protecting the document and in adopting appropriate safeguards); Memorandum of Opinion and Order, supra note 368 , at 14-16 (finding a waiver, despite the producing party having taken reasonable steps to prevent the disclosure, because it did not act diligently in rectifying the disclosure).

376. FED. R. EVID. 502(b) (“(b) Inadvertent Disclosure. When made in a federal proceeding or to a federal office or agency, the disclosure does not operate as a waiver in a federal or state proceeding if: (1) the disclosure is inadvertent; (2) the holder of the privilege or protection took reasonable steps to prevent disclosure; and (3) the holder promptly took reasonable steps to rectify the error, including (if applicable) following Federal Rule of Civil Procedure 26 (b)(5)(B)."); see also King, supra note 374, at 469.

377. King, supra note 374, at 502-03 (quoting FED R. EVID. 502(b), advisory committee's note).

378. This analysis especially holds when disclosure of specific, limited in- 
existence of problematic cases involving waiver, researchers should be careful to avoid inadvertently waiving the Certificate's protections or expanding the scope of the waiver. For example, researchers may want to avoid explicitly confirming the participation of any individual when research data are requested and to limit the amount of data shared in response to any request-compelled or otherwise. ${ }^{379}$ Scrupulously following confidentiality measures will make it easier for an attorney to argue for keeping the data confidential.

\section{B. IDENTIFIABILITY}

As has been discussed, Certificates of Confidentiality exist to protect the "names and other identifying characteristics of research study participants," not research data itself. 380 However, the term "other identifying characteristics" is not further defined within the statute. ${ }^{381}$ In its Frequently Asked Ques-

formation, such as disclosure of suspected abuse, was in no sense inadvertent but rather specifically foreseen and planned for (i.e., provided for in research protocols and consent forms, and the application for a Certificate). Applying for a Certificate would also be evidence of the researchers taking appropriate steps to protect the security of the data. All researchers should also follow basic confidentiality measures (what some have referred to as "Security 101"), including limiting who has access to the data (particularly identifiers), using password protection on electronic files, storing data in locked cabinets and offices, and coding data whenever feasible and keeping code links separate from the data.

379. In the Bradley case, Duke took this type of approach by fighting the subpoena without indicating whether the witness was, in fact, a research participant in the study from which data was sought. Compelled Disclosure of Data, supra note 23 , at 1054 . We recognize, however, that fighting a subpoena for data protected by a Certificate may be interpreted as confirmation of participation.

380. FAQs on Certificates, supra note 1. Specifically, NIH states that "[r] esearchers can use a Certificate to avoid compelled 'involuntary disclosure' (e.g., subpoenas) of names and other identifying information about any individual who participates as a research subject (i.e., about whom the investigator maintains identifying information) during any time the Certificate is in effect." Id. (emphasis added). Thus, the NIH Certificate kiosk mirrors the language in the authorizing statute, which allows researchers "to protect the privacy of individuals who are the subject of such research by withholding from all persons not connected with the conduct of such research the names or other identifying characteristics of such individuals." 42 U.S.C. $§ 241(\mathrm{~d})$ (2006) (emphasis added).

381. 42 U.S.C. $§ 241(d)$ (2006). The lack of a precise definition can be seen in similar language contained in other privacy protection statutes. See The Privacy Act of 1974, 5 U.S.C. $§ 552 \mathrm{a}(\mathrm{a})(4)$ (2006) (defining an individual's "record" as a "grouping of information about an individual ... that contains "his 
tions on the Certificate kiosk, NIH indicates that "other identifying information" includes details such as the "name, address, social security or other identifying number, fingerprints, voiceprints, photographs, genetic information or tissue samples, or any other item or combination of data about a research participant which could reasonably lead, directly or indirectly by reference to other information, to identification of that research subject." 382 However, despite this expansive definition of "identifying characteristics," it is unclear what information can make an individual "readily identifiable" and, thus, should be protected by a Certificate.

When the Certificate protection was first adopted in 1970 , the focus on name and other identifying characteristics made sense. ${ }^{383}$ Particularly in its earliest incarnation, the risk to individuals came from being identified as a user of illegal drugs. ${ }^{384}$ However, as technology has advanced, concerns about how data may be used and how to protect private information have evolved. An apt example of this movement can be seen in the Health Insurance Portability and Accountability Act of 1996 (HIPAA) ${ }^{385}$ and its accompanying regulations promulgated by the Department of Health and Human Services, Standards for Privacy of Individually Identifiable Health Information. ${ }^{386}$ Spurred by an understanding that advances in technology and practice had undermined the ability of traditional common law doctrines to protect personal health information, HIPAA and its accompanying regulations sought to

name, or the identifying number, symbol, or other identifying particular assigned to the individual, such as a finger or voice print or photograph"); Confidential Information Protection and Statistical Efficiency Act of 2002, 44 U.S.C. § 3501 note (2006) (defining "identifiable form" as "any representation of information that permits the identity of the respondent to whom the information applies to be reasonably inferred by either direct or indirect means").

382. FAQs on Certificates, supra note 1. Again, the NIH's description is consistent with the regulation, which defines "identifying characteristics" as "name, address, any identifying number, fingerprints, voiceprints, photographs or any other item or combination of data about a research subject which could reasonably lead directly or indirectly by reference to other information to identification of that research subject." 42 C.F.R. § 2a.2(g) (2011).

383. Guidance on Certificates of Confidentiality, NAT'L InstS. HEALTH, http://www.hhs.gov/ohrp/policy/certconpriv.html (last visited Oct. 18, 2012).

384. Id.

385. Health Insurance Portability and Accountability Act of 1996, Pub. L. No. 104-91, 110 Stat. 1936 (codified as amended in scattered sections of 18 U.S.C., 26 U.S.C., 29 U.S.C., and 42 U.S.C.).

386. 45 C.F.R. $\S \S 164.500-534$ (2011). 
provide a national standard for protecting health information, including defining eighteen pieces of information considered to be identifying. ${ }^{387}$ Despite this extensive list, some have begun to fear that re-identification of individuals may be possible no matter how many "identifying characteristics" have been removed from released data. ${ }^{388}$

Recent studies demonstrate so-called "anonymized" data can sometimes be re-identified using publicly available information. ${ }^{389}$ In the mid-1990s, Dr. Latanya Sweeney demonstrated that she could identify eighty-seven percent of individuals by combining three simple identifiers: five-digit ZIP code, birth date (including year), and sex. ${ }^{390}$ Similarly, in 2006, both AOL and Netflix participated in large scale data releases which led to re-identification of individuals. Spurred by a vision of an

387. 45 C.F.R. $§ 164.514(b)(2)$. The list of identifiers includes: "[n]ames," "geographic subdivisions smaller than a state," "[a]ll elements of dates (except year) ... related to an individual" (including dates of admission, discharge, birth, death and, for individuals over eighty-nine-years old, the year of birth must not be used), "[t]elephone numbers," "[f]ax numbers" "[e]lectronic mail addresses," "[s]ocial Security numbers," "[m]edical record numbers," "[h]ealth plan beneficiary numbers" "[a]ccount numbers," "[c]ertificate/license numbers," "[v]ehicle identifiers and serial numbers, including license plates," "[d]evice identifiers and serial numbers," web URLs, internet protocol addresses, "[b]iometric identifiers, including finger and voice prints" "[f]ull face photos and comparable images" and "[a]ny unique identifying number, characteristic or code." Id. Data without these identifiers are considered "deindentified" and available for research without consent.

388. Paul Ohm, Broken Promises of Privacy: Responding to the Surprising Failure of Anonymization, 57 UCLA L. REV. 1701, 1704 (2010). Ohm argues that "[d] ata can be either useful or perfectly anonymous, but never both." Id.

389. See Robert Gellman, The Deidentification Dilemma: A Legislative and Contractual Proposal, 21 Fordham InTELL. PROP. MEDIA \& ENT. L.J. 33, 37 (2010); Ohm, supra note 388, at 1716-22; Paul M. Schwartz \& Daniel J. Solove, The PII Problem: Privacy and a New Concept of Personally Identifiable Information, 86 N.Y.U. L. REV. 1814, 1836-43 (2011); Jane Yakowitz, Tragedy of the Data Commons, 25 HARV. J. L. \& TECH. 1, 31-33, 39-41 (2011). While these are not human subjects research data, they are useful for understanding the challenges to deidentification in light of today's technology and widely accessible information.

390. Latanya Sweeney, Simple Demographics Often Identify People Uniquely 2 (Carnagie Mellon Univ., Data Privacy Working Paper No. 3, 2000). To drive the point home, Dr. Sweeney identified then Massachusetts governor, William Weld's, medical records from data released by the Massachusetts Group Insurance Commission (GIC), which summarized every state employee's hospital visits and was available at no cost to any researcher who requested the records, based on his zip code, birth date and gender. Latanya Sweeney, k-Anoymity: A Model for Protecting Privacy, 10 INT'L J. UNCERTAINTY, FUZZINESS \& KNOWLEDGE-BASED SYS. 557, 558-59 (2002). 
"open research community," AOL released twenty million search queries created by 657,000 AOL users that, despite AOL's efforts to anonymize the data, were often relinked to individuals. ${ }^{391}$ Netflix's release of one hundred million records showing how nearly 500,000 users had rated movies on Netflix over a period of six years similarly resulted in re-identification of users. ${ }^{392}$ Despite what these examples suggest about our ability to protect individuals' confidentiality through removal of identifying information, others maintain that it is still possible to maintain confidentiality through the removal of personally identifying information. ${ }^{393}$ Additionally, a study conducted by the Department of Health and Human Services Office of the National Coordinator for Health Information Technology ("ONC") demonstrates how challenging it is to re-identify data properly de-identified under HIPAA. ${ }^{394}$ Of the 15,000 datasets

391. Michael Barbaro \& Tom Zeller, Jr., A Face is Exposed for AOL Searcher No. 4417749, N.Y. TIMES, Aug. 9, 2006, at A1. AOL took steps to anonymize the data, including assigning each searcher a numerical code name. Id. Nevertheless, bloggers and researchers pouring over the databases were able to reidentify individuals from information in the released data. Id.

392. The Netflix Prize Rules, NETFLIX, http://www.netflixprize.com/rules (last visited Apr. 6, 2012). Like AOL and GIC, Netflix took steps to anonymize the data by assigning unique user identifiers. Arvind Narayanan \& Vitaly Shmatikov, How to Break the Anonymity of the Netflix Prize Dataset, ARVIX (Oct. 16, 2006), http://www.citebase.org/abstract?id=oai:arXiv.org:cs/0610105. For each user, Netflix revealed the movie rated, the rating given, and the date of the rating. $I d$. Two weeks after the release, two researchers at the University of Texas showed that, using user ratings on the Internet Movie Database (IMDb), they were able to re-identify individuals in the Netflix Prize Dataset. Id. Scholars note the Netflix study is a perfect example of a piece of information that had not been considered personally identifying informationmovie ratings_-becoming an identifier. See Ohm, supra note 388, at 1742 ("The trouble is that PII is an ever-expanding category. Ten years ago, almost nobody would have categorized movie ratings and search queries as PII, and as a result, no law or regulation did either."); Yakowitz, supra note 389, at 25 ("Their study illustrates how the Internet is a (relatively) new public information resource that blurs the distinction between non-identifiers and indirect identifiers. The Internet affects data anonymization by archiving and aggregating large quantities of information and by making information gathering practically costless. It also provides a platform for self-revelation and selfpublication, making the available range of information about any one person unpredictable and practically limitless.").

393. See generally Yakowitz, supra note 389, at 44-50 (offering an improved approach to the release of anonymized data).

394. Deborah Lafky, The Safe Harbor Method of De-Identification: An Empirical Test (2009), available at http://www.ehcca.com/presentations/ HIPAAWest4/lafky_2.pdf. The study asked, "Can a Safe Harbor de-identified data set be combined with readily available outside data to re-identify data set subjects?" Id. at 6 . To determine this question, the study first pulled approxi- 
in the study, the team was only able to correctly and accurately identify two individuals, for a match rate of $0.01 \% .395$

While these examples animate the broader debate about whether deidentification is ever feasible, for our purposes, they serve to illustrate how the world has changed since Certificates were first adopted in 1970, and to suggest that our understanding of what Certificates protect needs to adapt to that world. In particular, to keep confidentiality promises to research participants, the research community needs to be prepared to articulate how seemingly unidentified data could be "readily identifiable" and, therefore, protected by a Certificate.

Some courts that have addressed statutory language similar to 42 U.S.C. $\S 241(\mathrm{~d})$ and the regulations in determining whether revealing certain types of data may lead to reidentification of specific individuals have adopted a broader conception of "identifiability." For example, in Hassig v. New York State Department of Health, the petitioners sought to "implement a cancer prevention program in St. Lawrence County," and requested records from the Department of Health under the Freedom of Information Law. ${ }^{396}$ Petitioners specifically requested "records from the State Cancer Registry of "cancer site specific diagnoses and deaths from the period of 1976-1997 for St. Lawrence County." 397 In addition to this information, the petitioners sought "information for all age groups ... except in those instances where there were two or less cancer site specific records for a particular year and zip code." 398

The Department of Health denied the petitioners' requests

mately 15,000 Safe Harbor method de-identified patient records. Id. at 16. To increase the likelihood of an "easy" match, all of the records pulled selfidentified as part of a large minority ethnic group. Id. The researchers then manually compared the deidentified datasets with identifiable records from a commercially available data repository. The researchers explained that the decision to go through the re-identification process manually stemmed from the fact that "[t]here are no matching algorithms the team knows of that are more accurate than using human judgment because (a) contextual knowledge is essential" and "(b) data sources are "dirty." Id. at 19. The study concluded that matching up Safe Harbor de-identified data with publicly available information is labor-intensive, costly, demonstrates a low yield, and that under most circumstances, the Safe Harbor method of de-identification protects against re-identification. $I d$.

395. Id. at 19.

396. Hassig v. N.Y. State Dep't. of Health, 294 A.D.2d 781, 781 (2002).

397. Id.

398. Id. 
on the basis of two statutes. ${ }^{399}$ First, the Department referred to Public Health Law $\S 2402$ which states, "The reports of cancer cases made pursuant to the provisions of [Public Health Law article 42] shall not be divulged or made public so as to disclose the identity of any person to whom they relate, to by any persons...." 400 Second, the Department relied upon 42 U.S.C. $§ 280(\mathrm{e})$, which prohibits the "disclosure to any person of information ... that identifies, or could lead to the identification of, an individual cancer patient." 401 Relying on these statutory provisions, the Department argued that providing the information requested by the petitioners "could lead to the disclosure of the identity of a particular cancer patient" and must be denied. ${ }^{402}$ In support of this argument, the Department produced an affidavit by the Director of the State Cancer Registry outlining "possible scenarios under which the information sought by petitioners could, in combination with other readily available information, be used to identify specific cancer patients." 403 Relying solely on the affidavit produced by the Department, the court found that the Department had "articulated a particularized and specific justification for denying access to the records in question-namely, that such records, when combined with other readily available information, including community knowledge, could identify or lead to the identification of individual cancer patients." 404 Thus, the court accepted the possible scenarios outlined by the Department as potentially identifying and denied the petitioners' requests without further inquiry into the question of possible re-identification of the cancer patients. 405

In contrast, in Southern Illinoisan v. Illinois Department of Public Health, while the Supreme Court of Illinois considered the impact of technology in determining whether the requested information could potentially lead to re-identification, it ultimately took a narrower view on what counted as "identifiable."406 In that case, the Southern Illinoisan newspaper re-

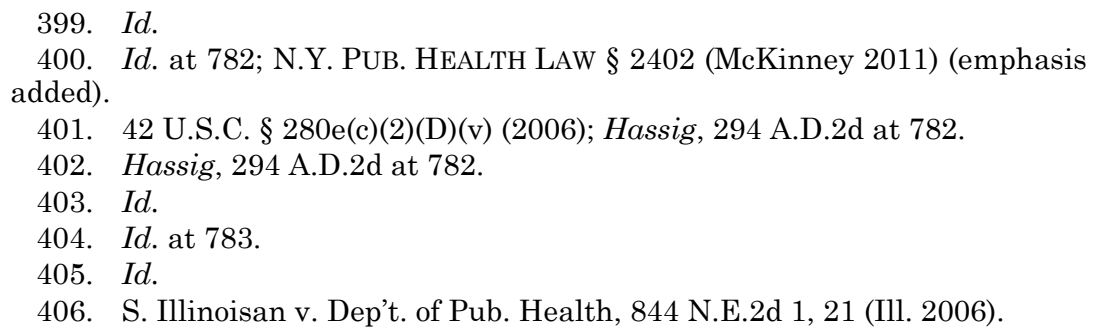


[Vol. 14:1

quested information from the Illinois Health and Hazardous Substances Registry (Cancer Registry) "about incidents of neuroblastoma, a rare form of childhood cancer." 407 The requested information included the type of cancer, zip code, and date of diagnosis of each incidence of neuroblastoma within Illinois from 1985 to the present. ${ }^{408}$ The Department denied the request, and the newspaper then filed a complaint to evaluate the denial pursuant to the Freedom of Information Act. ${ }^{409}$

At a bench trial, the Department relied upon two statutory provisions in support of the denial. First, the Department argued that the Registry Act precluded the Department from disclosing any information that revealed "the identity, or any group of facts which tends to lead to the identity, of any person whose condition or treatment is submitted to the Illinois Health and Hazardous Substances Registry." 410 Thus, the Department argued that the Illinois Freedom of Information Act, which exempts from disclosure "[i]nformation specifically prohibited from disclosure by ... State law or rules and regulations adopted under ... State law," forbade the disclosure. ${ }^{411}$ In support of this argument, the Department presented Dr. Latanya Sweeney as an expert witness on data anonymity. ${ }^{412}$ Dr. Sweeney opined that it would be very easy for anyone with a computer and readily available software to reidentify persons from the Cancer Registry using public data sets. ${ }^{413}$ The circuit court, however, disagreed, concluding after an in camera review of Dr. Sweeney's methodology that non-experts could not complete the re-identification that Dr. Sweeney had and, thus, the information requested "will not reasonably tend to lead to the

\footnotetext{
407. Id. at 2 .

408. Id. at 3 .

409. Id.

410. Id. at 4; 410 ILL. CoMP. STAT. 525/4(d) (2011).

411. S. Illinoisan, 844 N.E.2d at 4 (quoting 5 ILL. CoMP. STAT. 140/7(1)(a) (West 2011)).

412. Id. at 7. Dr. Sweeney was qualified as an expert based on her undergraduate degree in computer science from Harvard University, master's degree in computer science and electrical engineering from MIT, and a Ph.D in computer science from MIT, and her extensive experience in "numerous cases involving data privacy questions and the anonymity of data." Id.

413. Id. at 8-9. Using similar techniques to those she used in the Massachusetts health information example described above, Dr. Sweeney was able to reidentify eighteen of twenty individuals whose data was contained in the Cancer Registry based on the pieces of information requested by Southern Illinoisan and anything else she could find from public sources. Id. at 7 .
} 
identification of individuals" and ordered production of the data. ${ }^{414}$

Both the Appellate and Supreme Courts agreed with the Circuit Court's determination. The appellate court elaborated on the circuit court's reasoning, explaining that:

[T] he fact that one expert in data anonymity can manipulate data to determine identity does not necessarily mean, without more, that a threat exists that other individuals will be able to do so as well, nor does it in any way define the magnitude of such a threat or whether that threat, if it in fact even exists, renders the release of the data an act that reasonably tends to lead to the identity of specific persons. To find otherwise would undermine the reasonableness requirement and would effectively remove it from our analysis, leading to a situation where if it could be shown that one expert could identify individuals from information released, then the release of that information would automatically be deemed to reasonably tend to lead to the identity of specific persons. ${ }^{415}$

The Illinois Supreme Court affirmed the decision of the Appellate Court. ${ }^{416}$

The disagreement about identifiability represented by these two cases is similarly found in the Certificate cases. The Attorney General's opinion in the Louisville case took the broader view, explicitly considering how the data could be combined with other information to identify individual research participants with potentially negative consequences. ${ }^{417}$ On the other hand, other courts have ordered production of data from a small number of research participants, when the requester already had identified data about them as litigants, rendering them potentially vulnerable to reidentification. ${ }^{418}$ Moreover, the courts in Bradley and the juvenile case were willing to compel production of particular individuals simply because the subpoenaing party knew the individual's name and had some information suggesting study participation. ${ }^{419}$ In order to respect research participants' expectations and maintain their trust in the confidentiality promises made to them, greater clarity is needed about what information should be considered "identifiable" and what data is actually protected when a Cer-

414. Id. at 5,9 .

415. Id. at 11 (quoting S. Illinoisan v. Dept. of Pub. Health, 349 Ill. App. 3d 431,436 (2004)).

416. Id. at 21 .

417. Op. Ky. Att'y Gen., supra note 137.

418. See, e.g., In re Phenylpropanolamine (PPA) Products Liability Litigation discussion supra Part II.D.

419. See discussion of these cases supra Part II.C-D. 
tificate is obtained. We would suggest that advances in technology and availability of vast amounts of information through the internet demand a broader concept of identifiability than may previously have been adopted. In the next part, we suggest ways to do so.

\section{Potential Ways For Strengthening the Protections of IDENTIFIABLE RESEARCH DATA}

Having identified these potential vulnerabilities, we must consider whether there are ways to strengthen the Certificate's protection. In doing so, we are assuming that doing so is desirable. We base our assumption on the support of Congress in maintaining the Certificate as a tool for researchers and expanding the range of research that is eligible for a Certificate, ${ }^{420}$ the NIH's decision to encourage increased use of Certificates, ${ }^{421}$ and the support for the Certificate we have heard from researchers, IRB Chairs, and legal counsel. ${ }^{422}$ There are several possible strategies for addressing the potential vulnerabilities and, thus, strengthening Certificates. These include both short and long term strategies. Because some may be more feasible politically, it may be advantageous to use multiple strategies.

The vulnerabilities we have identified arise because the concepts of waiver and identifiability are not defined in the statute, nor are they fully fleshed out in the regulations or NIH guidance. Amending the statute to address the effect that voluntary disclosure has on the continuing protections, and under what circumstances data are considered "identifiable" in light of technological and informational advances, would be the strongest approach. ${ }^{423}$ However, there are also drawbacks to this strategy. First, a statute may not be flexible enough to

420. See supra Part II.A.

421. Leslie E. Wolf et al., The Certificate of Confidentiality Application: A View from the NIH Institutes, 26 IRB 14, 14 (2004).

422. Wolf, supra note 17, at 6; Compelled Disclosure of Data, supra note 23, at 9; Leslie E. Wolf \& Jola Zandecki, Sleeping Better at Night: Investigators' Experiences with Certificates of Confidentiality, 28 IRB 1, 4-8 (2006).

423. Amending the statute would provide an additional opportunity to consider whether there are better ways to structure the Certificate's protections. For example, some of the other federal statutes and many of the state statutes provide coverage to research generally without requiring an application, and some provide a broader spectrum of coverage to the data. These features may be worth considering as an alternative to the current Certificate approach. 
keep up with the rapidly changing technology and increasing availability of information. Some of the specifics may be better addressed through regulations or guidance, which are more easily changed. Second, in the current political environment, getting any legislation passed is challenging, and, thus, it may not be feasible to implement statutory change.

It may be easier to put forward definitions through the regulatory process. Because the legislation enabling the Certificate program does not prescribe specific procedures or refer to the formal rulemaking procedures of the Administrative Procedure Act, the informal procedures of that Act govern any regulations HHS promulgates. ${ }^{424}$ An informal rulemaking procedure requires publication in the Federal Register of a notice of proposed rulemaking that includes the time and location of any upcoming rulemaking proceedings, "reference to the legal authority under which the rule is proposed," and a description of the terms, substance, or nature of the proposed rule. ${ }^{425}$ Informal rulemaking offers interested parties a chance to submit "written data, views, or arguments," leaving to the agency the option of allowing an opportunity for oral presentation. ${ }^{426}$ The Administrative Procedure Act requires the agency to include in its adopted rules "a concise general statement of their ...purpose." 427 Of course, there are political considerations to the regulatory process, as well, which may limit the ability to effectuate change. ${ }^{428}$

424. 1 Charles H. Koch, JR., Administrative LaW \& Practice $§ 2: 33$ (2d ed. 1997).

425. Adminstrative Procedure Act, 5 U.S.C. $\$ 553(b)$ (2006).

426. 5 U.S.C. $\S 553(\mathrm{c})$.

427. Id. The informal rulemaking process is, not surprisingly, easier than the formal rulemaking procedures under the Administrative Procedure Act. Id. $\S 556-57$. Formal rulemaking requirements include hearings in the presence of an impartial presiding officer, and a prohibition on ex parte communications among agency decision-makers and interested persons outside the agency. $I d$. $\S \S 556(\mathrm{~b}), 557(\mathrm{~d})(1)(\mathrm{A})$. Hearings for the purpose of a formal rulemaking may include subpoenas, evidentiary rulings, and depositions. Id. $\S 556(\mathrm{c})$. Interested parties to a formal rulemaking are entitled to present oral evidence and conduct cross-examination. $I d$. $\$ 556(\mathrm{~d})$.

428. In 2011, the Department of Health and Human Services issued an advance notice of proposed rule-making concerning proposed changes to the federal regulations governing human subjects research. Human Subjects Research Protections: Enhancing Protections for Research Subjects and Reducing Burden, Delay, and Ambiguity for Investigators, 76 Fed. Reg. 44512 (Jul. 26, 2011) (to be codified at 45 C.F.R. pts. $46,160 \& 164$, and 21 C.F.R. pts. 50 \& $56)$. Despite significant attention within the research community, and tens of thousands of responses, it is unclear at this point whether any changes will in 
An alternative to regulatory amendment is for HHS to issue guidance clarifying the nature of the protection afforded by a Certificate and how concepts of identifiability and waiver play into that protection. Distinct from "legislative rules," the term "guidance" includes a number of possible agency pronouncements that do not carry the force of law and are not made pursuant to delegated authority. 429 The category includes "interpretative rules" and "general statements of policy," both explicitly exempt from the notice-and-comment and hearing requirements of the Administrative Procedure Act.430 The term "guidance" also includes documents variously referred to as guidelines and manuals. ${ }^{431}$ A guidance document is final agency action subject to immediate judicial review. 432

While such guidance can be useful to individuals interacting with the agency (e.g., in this case, can enhance researchers' and IRBs' understanding of Certificates), it also has legal significance. While not entitled to as much deference as regulations that interpret a statute that is silent or ambiguous on an issue, ${ }^{433}$ agency guidance is entitled to some deference by reviewing courts, referred to as Skidmore deference. ${ }^{434}$ In Skidmore, the Supreme Court described the factors affecting the weight that should be given guidance documents:

We consider that the rulings, interpretations and opinions of the Ad-

fact be made to the regulations.

429. KocH, JR., supra note 424, § 1:20.

430. 5 U.S.C. § 553(b), (d) (2006); KoCH, JR., supra note 424, § 1:20.

431. KocH, JR., supra note 424, § 1:20.

432. Appalachian Power Co. v. E.P.A., 208 F.3d 1015, 1020-21 (D.C. Cir. 2000). See also Barrick Goldstrike Mines Inc. v. Browner, 215 F.3d 45, 48 (D.C. Cir. 2000) (finding that a guidance document is final if it constituted the consummation of the agency's decision-making process and determined rights and obligations with legal consequences).

433. See Chevron v. Natural Resources Defense Council, 467 U.S. 837, 843-44 (1984) (holding that courts must defer to an agency's reasonable statutory interpretation where Congress has made an implicit agency delegation). In Chevron, the Court reviewed an E.P.A. regulation allowing a state to define the term "stationary source" to include an entire plant, rather than a particular pollution-emitting device. Id. The regulation had been promulgated according to formal procedures and published in the Code of Federal Regulations. Id. at $840-41,853,855$.

434. United States v. Mead Corp., 533 U.S. 218, 241 (2001). The Court has ruled that "interpretive rules ... enjoy no Chevron status as a class." Id. at 232. However, guidance documents are entitled to Skidmore deference. Christensen v. Harris County, 529 U.S. 576, 585-87 (2000) (relying on cases in which Skidmore deference was used for guidance documents). 
ministrator under this Act, while not controlling upon the courts by reason of their authority, do constitute a body of experience and informed judgment to which courts and litigants may properly resort for guidance. The weight of such a judgment in a particular case will depend upon the thoroughness evident in its consideration, the validity of its reasoning, its consistency with earlier and later pronouncements, and all those factors which give it power to persuade, if lacking power to control. ${ }^{435}$

As Koch explains, "Skidmore deference means that the agency's interpretation is compelling only if it has the "power to persuade' as opposed to Chevron deference by which the agency's view must be accepted if "reasonable." 436 Koch further notes that courts reviewing guidance pronouncements generally give them more weight when they contain one or more of these characteristics, either because they are following Skidmore or through their own instincts. $437 \mathrm{He}$ concludes, "In the end, the persuasiveness is the key." 438 Courts have consistently found that longstanding pronouncements deserve great deference.

While deference is not guaranteed, HHS should take advantage of the experience it has with Certificates to educate courts about their purpose and scope. It already does so to some extent through the NIH Certificate kiosk. The kiosk contains a wide variety of information, from basic instructions for investigators, to information about the statute authorizing Certificates, to contact information for NIH legal counsel. 439 However, HHS could expand this information to provide more guidance regarding how it views the Certificates it issues, issues that have arisen, and how those issues have been resolved. 440 Pro-

435. Skidmore v. Swift \& Co., 323 U.S. 134, 140 (1944).

436. KoCH, JR., supra note 424, § 11:30.

437. Id.

438. Id

439. Certificates of Confidentiality Kiosk, U.S. DeP'T HEALTH \& HUM. SERVICES, http://grants.nih.gov/grants/policy/coc/ (last updated Sept. 4, 2012).

440. While the current guidance is issued by NIH, it is not clear whether this is done with official delegated authority that would make it more likely that it would receive Skidmore deference. The Certificate implementing statute grants authority only to the Secretary of HHS, although the regulation defines "secretary" as "the Secretary of Health and Human Services and any other officer or employee of the Department of Health and Human Services to whom the authority involved has been delegated.” 42 U.S.C. § 241(d) (2006); 42 C.F.R. § 2a.2(a) (2011). This suggests that the Secretary could delegate authority to someone within NIH knowledgeable about Certificates. Such delegation is consistent with the General Administration Manual, which outlines agency policy whereby an organization within the agency may request a writ- 
vided the guidance is consistent with its overall position, which has supported strong confidentiality protections, courts would likely welcome guidance on this otherwise unfamiliar topic. In any event, issuing guidance is likely to be the easiest to accomplish $^{441}$ and, therefore, may a good short-term strategy.

Even if more detailed guidance from HHS does not get deference in judicial decision-making, such guidance can be beneficial from an educational standpoint. As our data indicated, attorneys do not confront Certificate issues frequently in their careers, and, thus, are unlikely to develop expertise in the area. Judges are even less likely to confront Certificate issues because attorneys often resolve them outside of court. Accordingly, attorneys and judges need resources to help them get up to speed on this relatively unique protection. HHS, through the $\mathrm{NIH}$, may be in the best position to provide useful resources. ${ }^{442}$ In addition to knowing what types of research are using Certificates, NIH is in a position to know about legal demands. The kiosk recommends that researchers contact the NIH Certificate coordinator who issued their Certificate when a demand is made and indicates that the "[t]he Office of the NIH Legal Advisor is willing to discuss the regulations with the researcher's attorney." 443 Accordingly, providing more detailed guidance could provide important, practical information to those confronting a legal demand involving a Certificate.

\section{CONCLUSION}

In sum, while Certificates have generally been effective as a deterrent to legal demands for research data and have also

ten delegation of authority from the Secretary by written request outlining the legal authority upon which the Secretary may delegate. U.S. DEP'T OF HEALTH \& Human Servs., General Administration MANuAL § 8-101-20(A) (2006) available at http://www.hhs.gov/hhsmanuals/administration.pdf. Generally, the legal authority exists unless specifically prohibited by statute. $I d$.

441. While this may be the "easiest" strategy, it does not mean that it is easily accomplished. The internal review process within an agency can be time-consuming and politically sensitive. However, at least it is all within the control of the agency, unlike regulatory or statutory amendments.

442. NIH already provides important information about Certificates through the Certificate kiosk, which we rely on frequently in our own work. Certificates of Confidentiality Kiosk, supra note 439. We are aware that the $\mathrm{NIH}$ has worked recently to reorganize the information on the website to make it more accessible to users. Personal Communication, Ann Hardy, NIH Certificate of Confidentiality Coordinator (Oct. 27, 2012).

443. FAQs on Certificates, supra note 1. 
been successful when disputes end up in court, those protections have some vulnerabilities, particularly arising from changing technological and informational advances. IRBs, researchers, and, presumably, research participants rely on Certificates to protect sensitive, identifiable research data and facilitate research on important public health issues. We owe it to them to ensure those protections are as strong as possible. We have suggested several ways, from increased guidance to amending the regulations and statute, that some of the uncertainty concerning Certificate's protections could be addressed. We have also highlighted broader protections offered by other federal statutes and state statutes as alternative models for modifying the Certificate structure. 